\title{
Lovecraft, Providence, Moore y el fin del logos
}

\author{
Roberto BArtual
}

\author{
Universidad de Valladolid
}

Roberto Bartual (Alcobendas, 1976) es doctor en Literatura Europea y publicó su tesis doctoral bajo el título de Narraciones Gráficas (Ed. Marmotilla). Su actividad académica se ha centrado en los orígenes del cómic y sus trabajos han sido publicados en revistas como Studies in Comics, Scandinavian Journal of Comic Art, Goya: Revista de Arte o Entre Lineas. También investiga sobre la estética psicodélica en el cómic y, al respecto, ha publicado el volumen monográfico Jack Kirby: Una Odisea Psicodélica (Ed. Marmotilla). Ha traducido a autores clásicos de la literatura inglesa (Emily Brönte) y de la narración gráfica (Alan Moore). Como escritor de ficción ha publicado una novela gráfica (Los Ángeles de María) y, muy próximamente, una novela de ciencia-ficción (Blitzkrieg, Ed. Cerbero). Ha editado La Casa de Bernarda Alba Zombi de Lorca y Jorge de Barnola, ilustrada por Nicolás Martínez Cerezo; y, junto con Gerardo Vilches, es coeditor del fanzine sobre Twin Peaks Querida Diane. Es profesor en el departamento de Filología Inglesa de la Universidad de Valladolid.

Fecha de recepción: 8 de noviembre de 2017

Fecha de aceptación definitiva: 9 de diciembre de 2017 


\title{
Resumen
}

La obra del escritor de Nueva Inglaterra, H. P. Lovecraft, ha sido adaptada numerosas veces al cómic y, en otras ocasiones, ha servido como inspiración para narraciones gráficas ambientadas en su universo ficticio. El terror lovecraftiano, al contrario de lo que parece, no está relacionado con el miedo a lo desconocido, sino con el miedo al conocimiento; de ahí que la aproximación de Alan Moore y Jacen Burrows a Lovecraft - The Courtyard, Neonomicon, pero, sobre todo, Providence - más que una recontextualización de su obra, suponga una relectura desde coordenadas mejor informadas, donde lo «terrorífico» no esconde sus perfiles, sino que se presenta como algo totalmente ajeno, pero completamente visible, cuya comprensión y conocimiento le obligan a uno a reconsiderar la naturaleza de la realidad.

En el presente artículo se analiza la última entrega de la saga lovecraftiana de Moore y Burrows, Providence, la cual funciona como una ficción y al mismo tiempo también como un ensayo sobre la naturaleza de Lo Numinoso en la obra de Lovecraft, explorando el papel de este concepto y de la gramática del Inconsciente Colectivo, así como el miedo a perder el dominio del lenguaje y, por tanto, de lo racional.

Palabras clave: H. P. Lovecraft, Alan Moore, arquetipos, Inconsciente Colectivo, logos.

\begin{abstract}
The writings of H. P. Lovecraft have been adapted many times to the comics medium, as well as serving as inspiration for graphic narratives set in his fictional universe. Lovecraftian horror is not related with the fear of the unknown but with the fear of knowledge. That is why Moore and Burrow's approach to Lovecraft - The Courtyard, Neonomicon and, especially, Providence - is not just a simple recontextualization of H.P.L.'s work, but a re-reading from new, more knowledgeable coordinates, where horrifying things do not hide their profiles but present themselves as something completely alien, but at the same time, perfectly clear and visible. Their intentions and aspect may not be that horrible, as it is, but knowing that they exist invariably lead Lovecraft's protagonists to reconsider the nature of reality.

In this article, I will analyze the last installment of Moore and Burrow's Lovecraftian saga, Providence, which works both as a fiction and an essay about the nature of The Numinous in Lovercraft's writings, exploring the role of this concept and also the role of the grammar of the Collective Unconscious, as well as the fear of losing control of language and reason.
\end{abstract}

Keywords: H. P. Lovecraft, Alan Moore, Archetypes, Colective Unconscious, logos.

\section{Cita bibliográfica}

Bartual, R. «Lovecraft, Providence, Moore y el fin del logos», en Cuco, Cuadernos de cómic, n. ${ }^{\circ} 9$ (2017), pp. 75-107. 


\section{Me cansas, Alan Moore}

Decir que Providence se encuentra, tal vez, entre los mejores textos de Alan Moore es, a estas alturas de la vida, como no decir nada. No decir nada porque, para alguien que ha dejado atrás una obra tan variada como Moore, los términos «mejor» o «peor» se han convertido en una mera cuestión de gusto, o de saber conectar mejor o peor con los diferentes estilos y géneros con los que ha ido experimentando a lo largo de su carrera. Eso por no decir que no tiene mucho sentido comparar sus cómics con su trabajo en otros medios en los que no ha sido tan prolífico, como por ejemplo pueden ser - muy incidentalmente- la música, la performance, el cine - apunta maneras - o la literatura — donde, al menos, cuenta con un logro monumental.

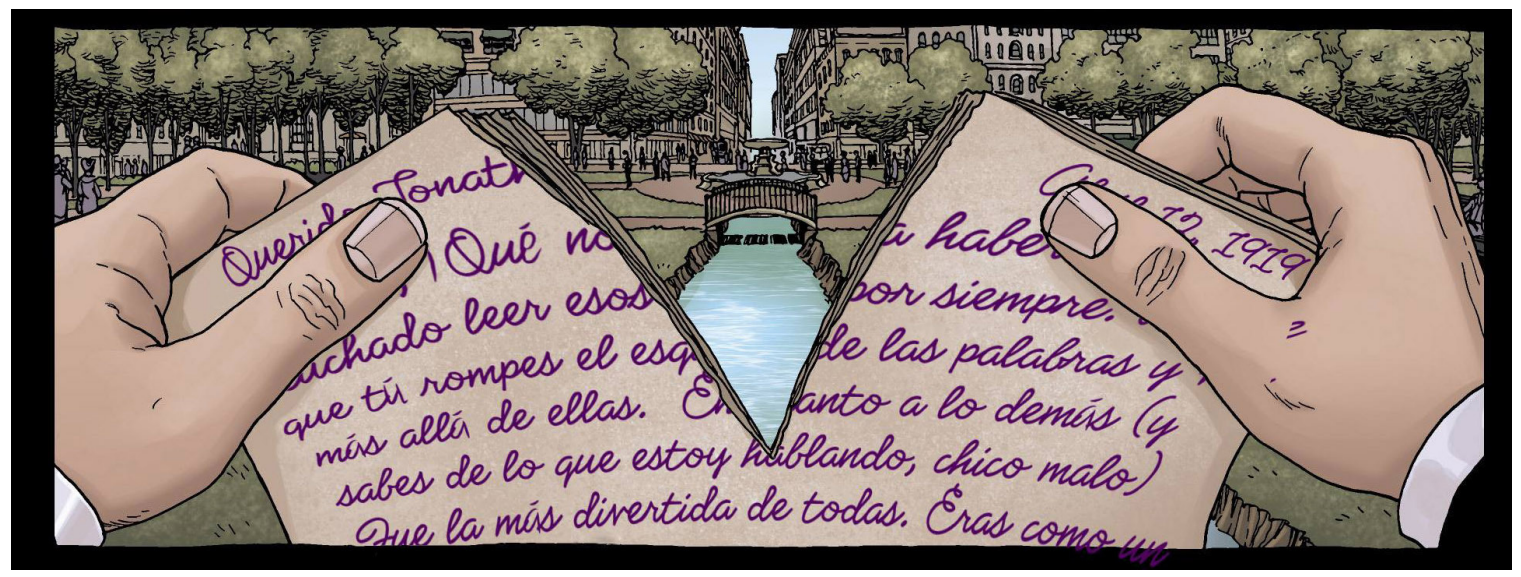

FIG. 1. Moore, A. y Burrows, J. Providence 1: El miedo que acecha. Madrid, Panini, 2016, ep. 1, p. 1. Traducción de Raúl Sastre.

Es cierto que, durante los últimos años, quizá desde que cerró su línea America's Best Comics, ha empezado a surgir cierta disensión con respecto a su trabajo; o, por lo menos, con respecto a su trabajo reciente en el medio del cómic. La única serie que sigue en proceso de publicación, The League of Extraordinary Gentlemen, ha ido haciéndose cada vez más rococó, convirtiéndose en un «¿Quién es quién?» cuyo interés, más que narrativo, reside más en acertar las preguntas de Trivial que esconde cada viñeta. Lost Girls, una maravilla para los sentidos, pone la zancadilla al lector a base de acumular reiteraciones narrativas bastante sádicas: no porque quiera maltratarnos, sino porque imita la muy farragosa prosa del Marqués de Sade. Crossed +100 es una muy estimable serie de zombis donde se pregunta qué diferencia hay entre nosotros y los muertos, solo para llegar a la misma conclusión que George Romero en Day of the Dead (1985); es decir, nada nuevo bajo el sol. Y, luego, también está Fashion Beast, el guion cinematográfico que hizo con Malcolm McLaren..., pero no voy a hablar de Fashion Beast. Cerremos los ojos y miremos hacia otro lado.

El caso es que, dentro del mundo del cómic, Moore no ha dado su mejor obra en los últimos años, cierto es; pero ¿qué más se le puede pedir a alguien que ha conquistado cimas incuestionables dentro de una diversidad de géneros tan grande? Por muy discutibles que 
puedan resultar títulos puntuales, ¿a alguien se le caerían los anillos por decir que La Cosa del Pantano es uno de los hitos principales alcanzados por el cómic de terror? ¿ $\mathrm{O}$ que Watchmen ocupa idéntico lugar dentro del cómic de superhéroes? Por no hablar de From Hell con respecto del género biográfico - en cómic o no-, Promethea del esotérico o $V$ de Vendetta del distópico. Y seguro que me dejo muchos títulos, pero el último autor que consiguió algo similar, tener la última palabra sobre tantos géneros narrativos diferentes en un determinado medio, fue William Shakespeare. Por eso, quizá tanta gente ha echado de menos durante estos últimos años al Moore de los ochenta e incluso al de los noventa. Y no les falta razón: por muy defendibles que sean los cómics que ha hecho en esta pasada década - y algunos, como Lost Girls, lo son bastante-, no es difícil reconocer que el principal de sus vicios estilísticos, la verbosidad, ha jugado muy en su contra estos últimos años.

Y no es que Moore se caracterizara antes por su parquedad de palabras: recordemos su querencia por el discurso en voz alta ya en Watchmen, esa obra donde, de golpe y porrazo, una mujer encuentra la respuesta a todos sus conflictos psicológicos cuando le sueltan un monólogo sobre el «Milagro Termodinámico». Alan Moore nunca ha escondido su principal problema: incluso él mismo reconoce en su última novela, en un capítulo dedicado a él mismo, que es un poco brasas. ${ }^{1}$ Sin embargo, esa tendencia suya a la sobreexplicación y al enunciar en lugar de sugerir - sobre todo en lo que se refiere a las ideas que hay detrás de sus narraciones - ha empezado a ser molesta para muchos, quizá porque no es lo mismo ser un brasas cuando hablas sobre cosas tan variadas como una fábula ecológica ( $\mathrm{La}$ Cosa del Pantano), o cuando hablas sobre el poder y sus mecanismos (Watchmen), o sobre la herencia simbólica de Occidente (Promethea), o sobre la crisis del estado de bienestar ( $V$ de Vendetta); no es lo mismo, insisto, ser un brasas cuando hablas de todas esas cosas tan diferentes, que serlo cuando hablas de una sola.

\section{El lenguaje}

El lenguaje por aquí, el lenguaje por allá. «Mmh, qué obra más interesante sobre el lenguaje... ¿Así que el lenguaje moldea la realidad? Quién lo iba a pensar (FIG. 2). Pero ¿cómo? ¿Que las ficciones son actos mágicos y, a través de ellos, se puede cambiar lo que piensa la gente de manera individual y colectiva?». Algo evidente para todo el que recuerde la obra de Joseph Goebbels, y no es que Moore se haya estado centrando en obviedades durante estos últimos diez años, pero su discurso monotemático sobre la ficción y el lenguaje — da igual que hable de zombis o de héroes victorianos- ya empezaba a resultar bastante cansino, o, por lo menos, abocado a un callejón sin salida, al que - y aquí vienen las buenas noticiasha sabido encontrársela milagrosamente tanto en Providence como en Jerusalem.

En Jerusalem eso ocurrió gracias a la ternura: ¿quién iba a decir que el durísimo e imperturbable Mago de Northampton iba a desnudarse emocionalmente de ese modo en un libro que

${ }^{1}$ Moore, A. Jerusalem. Nueva York, Liveright, 2016, pp. 1170-1202. Por usar un término un poco más amable que la palabra «pedante», que es precisamente lo que Moore sugiere en su novela. 


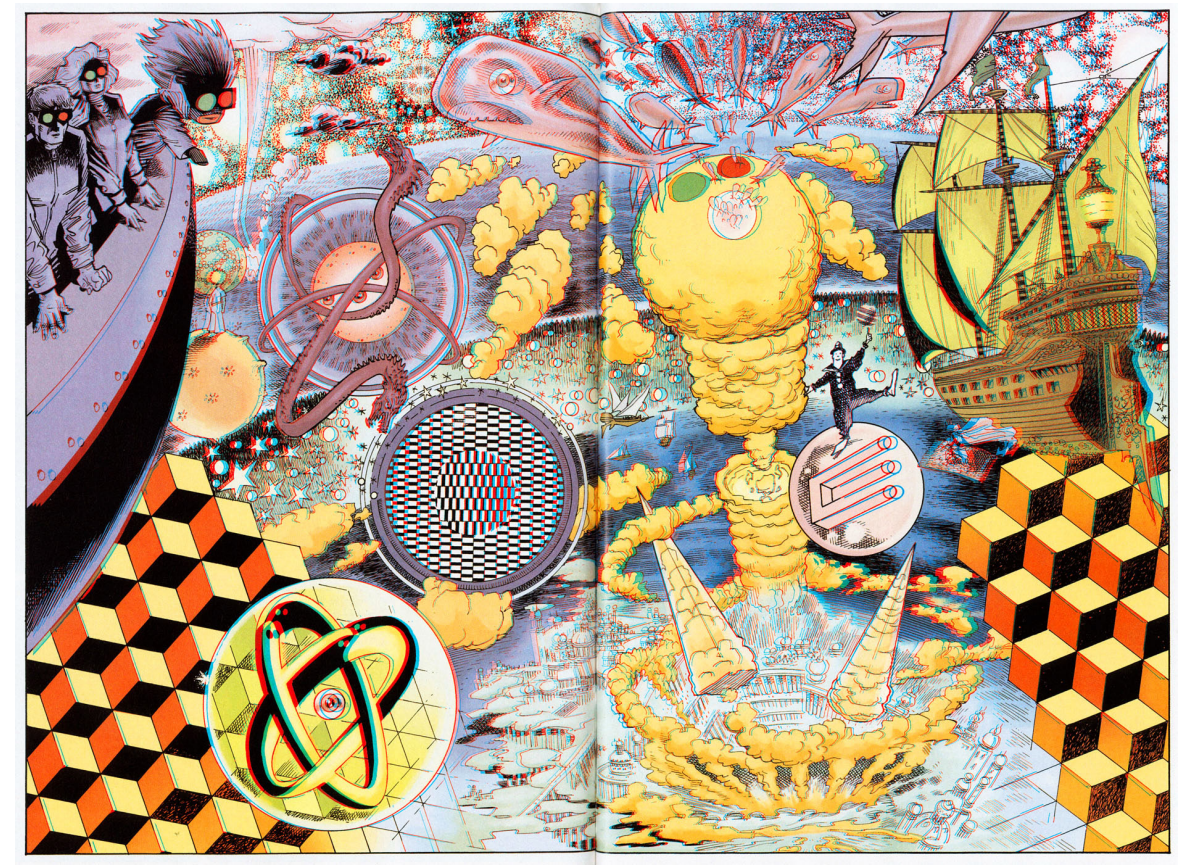

FIG. 2. Moore, A. y O'Neill, K. The League of Extraordinary Gentlemen: The Black Dossier. Marietta, Georgia, Top Shelf, 2007. Uno de esos típicos pasajes moorianos donde el lenguaje moldea la realidad, en este caso en 3D.

es, básicamente, un regalo de cumpleaños para su hermano pequeño? Providence, en cambio, de tierno no tiene nada. ¿Emociones humanas? No las busquéis aquí: el protagonista es un robot. Y, sin embargo, es el mejor robot que ha escrito Moore; con la profundidad humana que el Doctor Manhattan nunca pudo tener. No me atrevería a decir que es esto lo que redime a Providence por encima del monolitismo temático del resto de obras citadas anteriormente, pero lo cierto es que lo que plantea aquí Moore, la posibilidad de que H. P. Lovecraft inspirara sus cuentos en «hechos reales», sí me parece que eleva el discurso mooriano sobre el lenguaje y la realidad a un plano mucho más interesante. No tanto porque explore por enésima vez el vínculo que hay entre una cosa y la otra, sino por lo que supone de declaración de intenciones en su conclusión, en cuanto a su rechazo por la dimensión lingüística y racional del lenguaje, en favor de la dimensión puramente simbólica e irracional y, como se podrá ver al final de este artículo, por las implicaciones estéticas y políticas que esto tiene.

\section{H. P. Lovecraft}

Si alguna objeción se le ha hecho a Providence, ha estado dirigida hacia su artista, Jacen Burrows, ${ }^{2}$ dibujante también — por algo será- del resto de trabajos lovecraftianos de Moore:

${ }^{2}$ Daza, J. L. «Providence 1: El Miedo que Acecha», en Zona Negativa, 19 de julio de 2016. Disponible en: www.zonanegativa.com/providence-miedo-acecha/ 
el Neonomicon (2010-11) y The Courtyard (2003). Y es que tiene su retranca que la principal inspiración gráfica de un cómic basado en Lovecraft sea Tintín, y supongo que a los fans de Corben y Breccia se les coagulará la sangre al ver las narraciones del novelista de Nueva Inglaterra representadas con la hierática y rígida línea clara que caracteriza al estilo de $\mathrm{Bu}-$ rrows. Así que, en primer lugar, me parece necesario romper una lanza por el artista de esta obra, que en mi opinión solo podría haber sido sustituido por Dave Gibbons. En segundo lugar, además, creo vital justificar de una vez por todas, como quien defiende al diablo, que Lovecraft tiene en realidad más que ver con el estilo de Hergé que con el expresionismo — tirando a abstracto - de Breccia; igual que Poe tenía más que ver con Roger Corman que con los surrealistas franceses que adaptaron algunos de sus relatos - Jean Epstein, por ejemplo- - Y es que asociar a Lovecraft con el expresionismo y la abstracción está cerca de ser una idea preconcebida. Pero empecemos por ahí, porque para defender a Burrows tal vez sea mejor invertir el orden de mis propósitos y examinar si la abstracción tiene que ver o no con Lovecraft.

Dicen que Lovecraft juega a la baza de lo oculto, del terror innominado que se esconde en las sombras, del sugerir antes que mostrar, de que lo que da miedo es lo desconocido, lo que no vemos. Pues bien, no es verdad. Basta con leer detenidamente, muy detenidamente, relatos como «El que susurra en la oscuridad» (The Whisperer in the Darkness, 1930), donde los Mi-Go, unos bichos quitinosos que vienen de Plutón, parecidos a cangrejos alados, se dedican a aterrorizar a un habitante de las colinas de Vermont. Sin haber leído el relato, uno podría pensar que los crustáceos en cuestión se arrastran siempre por las sombras. Y es que el no saber si esa sombra es de un gato o de un bicho de Plutón es algo que da bastante miedo: y si no que se lo digan a Ridley Scott, que supo esconder muy bien al monstruo, encuadrándolo solo de forma fragmentaria, nunca su cuerpo entero, en una de las pocas películas que no hemos olvidado de él. Pero por mucho que Alien (1979) esté parcialmente basada ${ }^{3}$ en En las montañas de la locura (At the Mountains of Madness, escrita en 1931 y publicada en 1936), lo que hace Lovecraft en su novela es justo lo contrario. Si nos leemos bien El que susurra en la oscuridad, nos daremos cuenta de ello - aunque podemos probar con cualquier otra historia- Las descripciones de los $\mathrm{Mi}-\mathrm{Go}$, dignas de un bestiario medieval, son el sueño de cualquier criptozoólogo: el narrador no se deja ningún detalle en el tintero. Como ejemplo, un botón, que además, tiene su punto de ironía, pues se comienza aseverando que la criatura no puede ser descrita para, a continuación... describirla:

Su forma era indescriptible. Era como la de un cangrejo enorme con muchos anillos carnosos piramidales o nudos de algo grueso con el aspecto de cordeles, cubiertos por antenas allá donde

\footnotetext{
${ }^{3}$ No solo la exploración de un mundo gélido lleva a los expedicionarios a descubrir una civilización alienígena, sino que estos han de enfrentarse a una peligrosísima arma biológica inventada por dicha civilización; en el caso de la película de Scott y Dan O'Bannon es el Alien, mientras que en la novela de Lovecraft son los Shoggots, unos bichos gelatinosos que los Primordiales usan para tareas de carga y descarga. Si bien Alien (1979) se centra en los aspectos más terroríficos de esta premisa, es su precuela, Prometheus (2012), la película que mejor se ajusta al tono de la novela de Lovecraft, por cuanto recupera uno de los elementos más interesantes de su premisa original: la pregunta de quiénes son nuestros creadores y si podemos juzgarlos. Además, añade un indudable sentido de la maravilla que en En las montañas de la locura también aparece, siempre como contrapeso de sus aspectos más tenebrosos.
} 
debería haber habido una cabeza. La sustancia verde y pegajosa [que segregan] es su sangre o jugo vital. Y cada minuto hay más de ellos en la Tierra. ${ }^{4}$

Hay más descripciones a lo largo del cuento, tan gráficas como esta; y «gráfica» es precisamente la palabra, pues en ella no parece que Lovecraft esté describiendo la impresión subjetiva de un encuentro con un ser extraño, sino más bien como si estuviera detallando minuciosamente los rasgos de un sospechoso para hacer un retrato robot. De hecho, las ilustraciones de Howard H. Brown (FIG. 3) con las que se acompañó en su primera edición la obra más representativa de H. P., «At the Mountains of Madness» (en Astounding Stories, 1936), constituyen retratos exactos, detalle por detalle, de los seres descritos en el texto. Tomemos, por ejemplo, la de una de las criaturas que se encuentran los arqueólogos antárticos: un Antiguo (también llamados, a veces, Primordiales): ${ }^{5}$

Mide seis pies de longitud y tres pies y cinco décimas de diámetro central que disminuye hasta un pie de diámetro en cada punta. Semejante a un barril con cinco protuberancias abultadas en lugar de duelas. Rupturas laterales como tallos más bien finos a la mitad de estas protuberancias. En los surcos entre los abultamientos hay curiosas excrecencias - grandes crestas o alas que se pliegan y despliegan como abanicos- Todas están muy deterioradas, menos una, que alcanza casi siete pies una vez extendida. ${ }^{6}$

Y esta es solo la primera impresión del narrador: en la edición de bolsillo de Alianza, poco después de este párrafo, el narrador dedica cuatro páginas enteras, ¡cuatro!, a precisar los detalles anatómicos que se le han escapado tras aquella primera ojeada. ${ }^{7}$ Se trata de un informe redactado por un científico, cierto es, no la descripción de un observador ocasional; sin embargo, este tipo de descripciones casi entomológicas no son una excepción en la obra de Lovecraft, sino la norma general. Puede parecer extraño detallar en décimas de pies las diferencias de diámetro de las distintas partes del cuerpo de un ser desconocido, pero ¿no haría lo mismo cualquier biólogo? Sin embargo, no es necesario que los personajes de Lovecraft sean todos biólogos, como el doctor Lake, autor del informe arriba mencionado. Les basta con ser académicos para hacer uso del mismo estilo.

${ }^{4}$ Lovecraft, H. P. y Klinger, L. S. The Annotated H. P. Lovecraft. Nueva York, Liveright, 2016, p. 414. Traducción de Roberto Bartual.

${ }^{5}$ Los nombres de las diferentes especies del bestiario lovecraftiano pueden variar de traducción en traducción, incluso dentro de la misma editorial. Por ejemplo, Fernando Calleja traduce como «Primordiales» a los barrilitos de En las montañas de la locura, a quien Lovecraft dio el nombre de «Elder Things». Sin embargo, en «El que acecha en el umbral», de Derleth y Lovecraft, el traductor Rafael Llopis reserva el término «Primordial» para referirse, exclusivamente, al cuarteto de seres que están inmediatamente por debajo de los Dioses Exteriores; es decir: Cthulhu, Hastur, Shub-Niggurath y Nyarlathotep. Posteriormente, hay una cierta homogeneización de términos y estos últimos, para diferenciarlos de los Antiguos, han sido traducidos como «Primigenios». Derleth, A. y Lovecraft, H. P., «El que acecha en el umbral», en Los que vigilan desde el tiempo y otros relatos. Madrid, Alianza, 1981 [1945], p. 166.

${ }^{6}$ Lovecraft, H. P. En las montañas de la locura. Madrid, Alianza, 1981 [1936], p. 30. Traducción de Fernando Calleja.

${ }^{7}$ Ibid., pp. 31-34. 


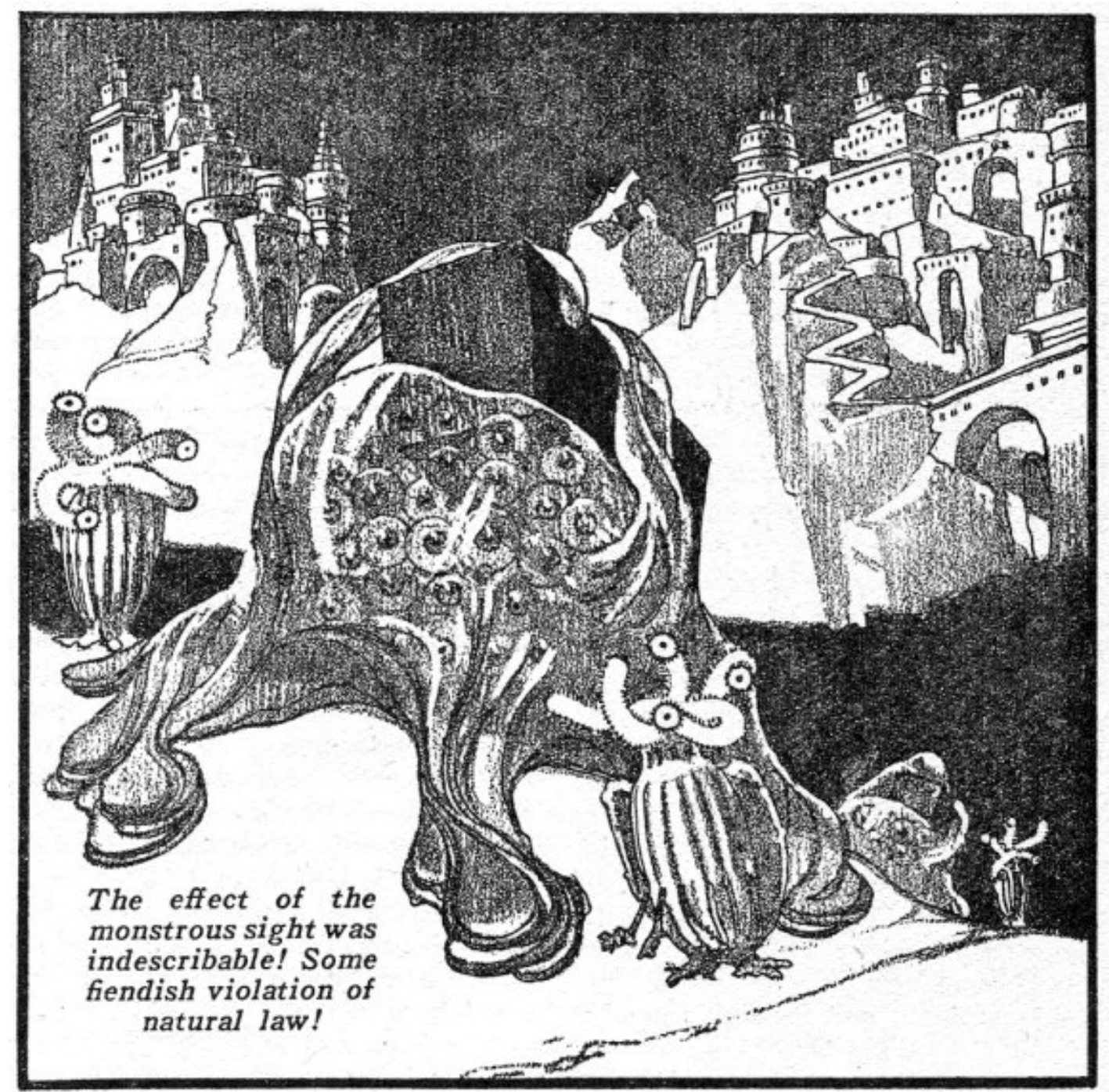

FIG. 3. Brown, H. H. «At the mountains of madness», en Astounding Stories, febrero de 1936. A derecha e izquierda, dos Antiguos. En el centro, un Shoggoth, bestia de carga al servicio de las anteriores criaturas.

Es una falsa idea que, a fuerza de ser repetida tantas veces, se ha llegado a tomar como verdad: que a Lovecraft le gusta sugerir, esconder sus horrores. Que le gusta hacernos sentir el miedo a lo desconocido. Pero nada más lejos de la realidad. Sus horrores están tan bien definidos que, si uno se fija realmente en las descripciones de «El que susurra en la oscuridad», cabría preguntarse por qué Breccia recurrió a un estilo tan cercano a las indefiniciones del expresionismo para retratar a los Mi-Go (FIG. 4).

El genio de Breccia residía en saber comunicar un estado de ánimo a través de su estilo gráfico; en este caso, el ambiente y la psicología malsana que preña la Nueva Inglaterra de los relatos. Sin embargo, este triunfo de la expresividad traiciona en cierto modo a Lovecraft, 


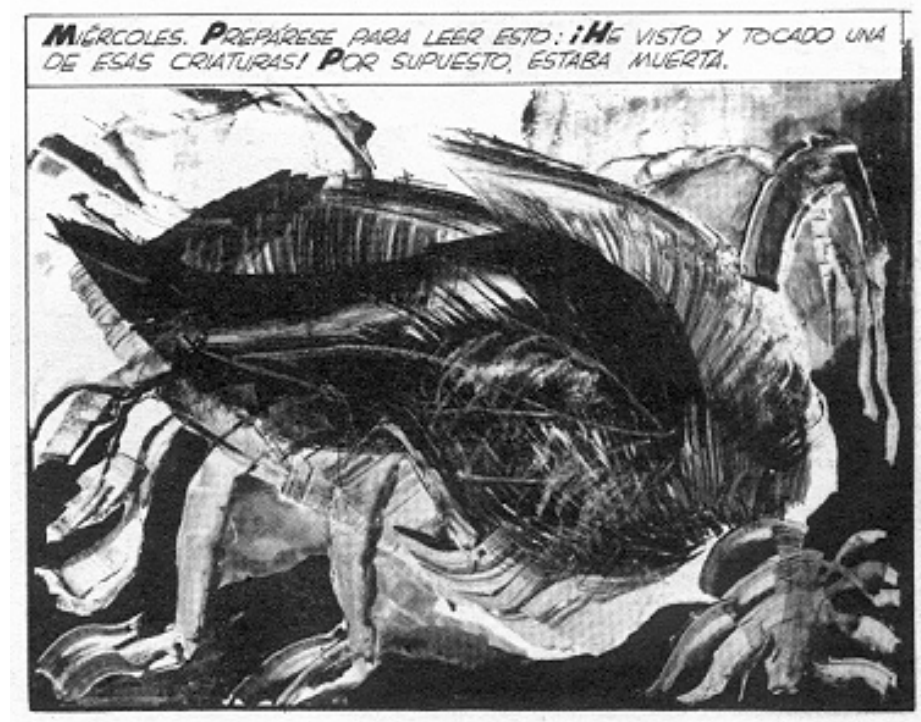

FIG. 4. Breccia, A. y Buscaglia, N. «El que susurra en la oscuridad», en Los mitos de Cthulhu. México D.F., Nueva Imagen, 1975, p. 34.

por lo menos en un aspecto. En realidad, los cuentos de Lovecraft no tienen que ver con el miedo a lo desconocido, sino con el miedo a lo conocido. No hablan del miedo que tenemos a que un extraño entre en nuestra casa o de que eso que se arrastra por tu pierna sea un bicho terriblemente espantoso y venenoso. Lovecraft da miedo porque te hace saber que una raza de cangrejos extraterrestres, cuyas características físicas se pueden consultar en el Necronomicón - y, a estas alturas, hasta en la Wikipedia-, está pululando por aquí, controlándonos para que no averigüemos demasiado sobre ellos. Si te atreves a consultar el libro maldito y les sacas un par de fotos, los Mi-Go te llevarán amablemente a su planeta para proteger su secreto. Sin embargo, si te callas y permaneces en la ignorancia conformándote con intuir las cosas a medias, entonces, no te pasará nada.

Es por todas estas razones que el estilo de Jacen Burrows me parece absolutamente adecuado para ilustrar las historias de Lovecraft. En primer lugar, porque se opone a las ideas preconcebidas sobre cómo se deben representar su bestiario y sus escenarios, arrojando luz sobre la oscuridad; y es que el verdadero terror de sus historias tiene lugar en el momento en que miramos cara a cara lo oculto (FIG. 5) o leemos el Necronomicón bajo la potente iluminación de la biblioteca de la Universidad del Miskatonic. Por otro lado, Burrows tiene ciertas limitaciones que, si uno lo piensa bien, resultan casi una ventaja a la hora de adaptar a Lovecraft. Porque Burrows tiene un tremendo talento para dibujar monstruos, decorados y paisajes urbanos, al mismo tiempo que demuestra una manifiesta incapacidad para hacer que los rostros de sus personajes sean lo suficientemente expresivos como para que sepamos si alguien abre la boca porque está gritando, porque está sorprendido o porque se está preparando para practicar una felación. En esto también se parece a Lovecraft: alguien que era incapaz de representar en sus protagonistas emociones humanas que no fueran el asco o la desesperación y que, sin embargo, era un absoluto maestro a la hora de 


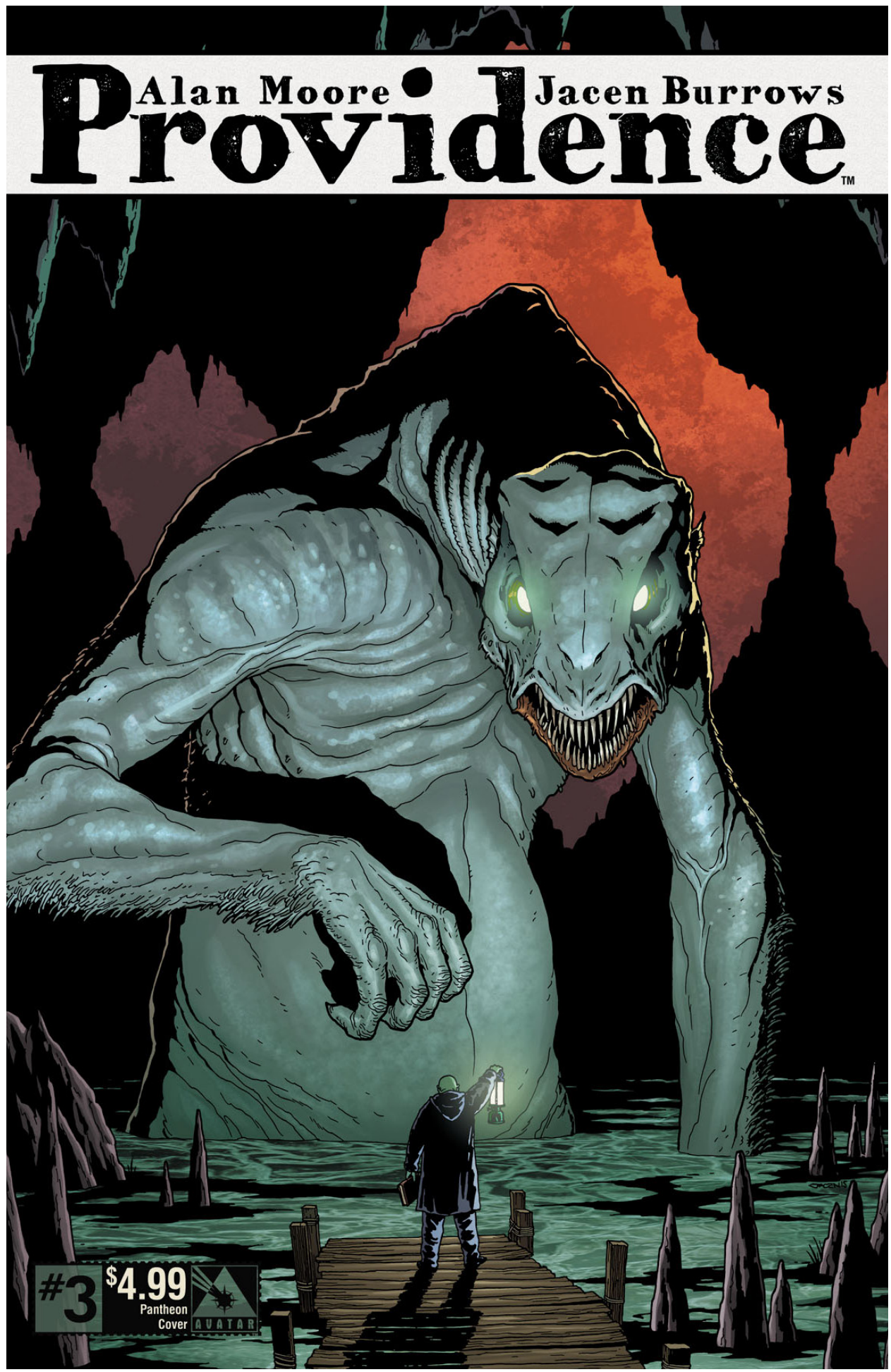

FIG. 5 Moore, A. y Burrows, J. Providence, 3. Rantoul, Illinois, Avatar Press, 2015. Cubierta correspondiente a la serie de portadas alternativas «Pantheon». 
usar las localizaciones - y los monstruos - para proyectar en ellas el resto de emociones reprimidas por el subconsciente de sus personajes.

\section{¿Recontextualizando a Lovecraft?}

Se ha presentado Providence como una recontextualización de la obra de Lovecraft ${ }^{8}$ por aquello de que Robert Black, su personaje principal, pese a compartir muchos rasgos con el típico narrador lovecraftiano - su labor de investigador, para empezar-, tiene una característica que H. P. jamás habría aceptado, y es que Robert Black es gay. Esto no constituye una recontextualización de los cuentos de Lovecraft, sino más bien leer entre líneas. Porque el así llamado «ciclo de Arkham», o ciclo de «los mitos de Cthulhu», está plagado de personajes masculinos que establecen fuertes relaciones entre ellos: normalmente, escribiéndose cartas para compartir conocimientos. Esto es así hasta el punto de que el apego que unos personajes sienten por otros es difícil de comprender si no postulamos otro tipo de relación. Así ocurre en «Herbert West: Reanimador» (1922), un cuento en el que, si no tratamos de imaginar una relación más física entre sus protagonistas, es difícilmente creíble que sigan juntos a la vista de los horrores que uno tiene que sufrir por culpa del otro. Moore no «relee» a Lovecraft. Tan solo enciende una linterna y enfoca lo que hay, lo que siempre ha habido en los rincones más polvorientos, tal vez aquellos que hemos pasado por alto al guiarnos por lo que creíamos saber sobre Lovecraft.

En el Providence de Moore y Burrows, Robert Black persigue la pista de un libro maldito, El libro de la sabiduria de las estrellas, a lo largo de lugares como Athol (Massachussets), Providence (Rhode Island) o Salem (Massachussets), donde tendrá encuentros con personajes similares a los que Lovecraft se refería en cuentos como «El horror de Dunwich», «El caso de Charles Dexter Ward» o «La sombra sobre Innsmouth», por mencionar solo aquellos ambientados en las localidades anteriores. Normalmente, los cuentos de Lovecraft tienen siempre la misma estructura. Un académico, un doctor, un niño rico que se aburre y lee mucho, lo que en el juego de rol denominaban con el maravilloso nombre de «diletante», gente diversa con bastante tiempo libre, en definitiva, se dedica a investigar un suceso o a un personaje del pasado. En el transcurso de dicha investigación se intuirán horrores inefables. Pero «inefable» es solo una manera de hablar, igual que Lovecraft usaba la palabra «indescriptible» en el pasaje anterior de «El que susurra en la oscuridad» para, a continuación, describir al monstruo. Es solo una manera de hablar porque, en algún momento, durante sus lecturas y pesquisas, el investigador lovecraftiano no solo descubrirá, con bastante exactitud, en qué consiste tal horror, sino también las consecuencias que este conlleva. Tales horrores pueden ser, por ejemplo, la existencia de una secta cuyos miembros son capaces de prolongar su vida indefinidamente ( $\mathrm{E} \mathrm{l}$ caso de Charles Dexter Ward»), la ascendencia marina de varias etnias de Massachussets («La sombra sobre Innsmouth») o el intento de un chiflado por traer al mundo una especie de Anticristo o de «Hijo de la Luna», como Aleister Crowley

8 Solinas, A. «Camino a Providence», en Moore, A. y Burrows, J., Providence, 1: El miedo que acecha. Barcelona, Panini, 2016. 
quiso hacer («El horror de Dunwich»). La reacción de quien investiga tales cosas es siempre la misma: en el mejor de los casos, acaba paralizado por un miedo preternatural; en el peor, acaba suicidándose al darse cuenta de que eso tan horrible que ha descubierto, no es más que la punta del iceberg de algo que trataré de discutir más adelante: la identidad en el Otro.

La actitud de Robert Black hacia lo que descubre es, sin embargo, bien diferente en el tebeo de Moore y Burrows. Pero es que Black ha sufrido una reciente desgracia que hace que su punto de vista sobre la materia que investiga sea bien distinto al del protagonista típico de los cuentos de Lovecraft. El novio de Black era travesti, cosa que Black jamás aceptó, o, por lo menos, no aceptó que su novio hiciera exhibición de ello. Lilly, se llamaba el monstruo. $\mathrm{Y}$ a Black no le gustaba que el monstruo hiciera precisamente aquello que encontramos en la etimología de la palabra: mostrarse (FIG. 6). Al no poder soportar la vergüenza y la armarización a la que le somete su novio, Lilly se suicida; y Black, quien tampoco es capaz de aceptarse a sí mismo, se lanza tras El libro de la sabiduría de las estrellas, en principio como un pretexto para huir de lo suyo y quién sabe si para comenzar una carrera literaria.

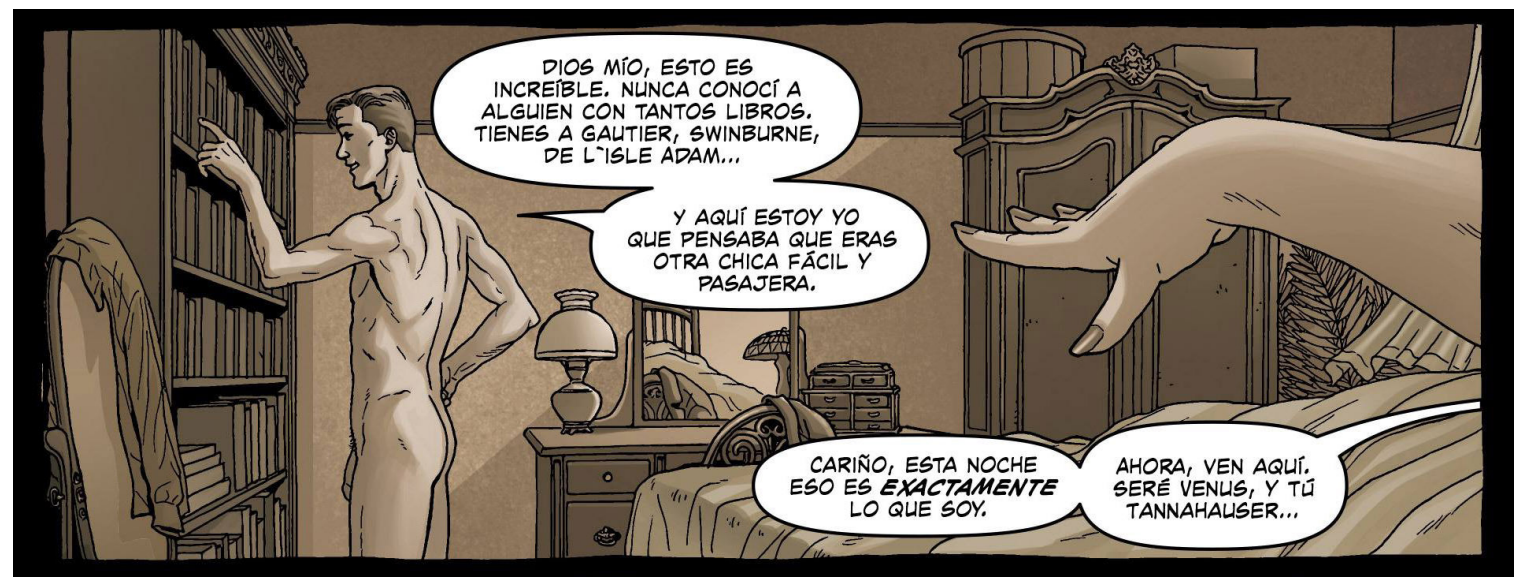

FIG. 6. Moore, A. y Burrows (2016). Op. cit., ep. 1,p. 11. En un gesto profundamente irónico, el único «monstruo» que no se enseña en Providence es Lilly, quien siempre aparece fuera de cuadro. Sin embargo, Burrows no tiene ningún reparo en mostrarnos cara a cara a Nyarlathotep (Johnny Carcosa), Azathoth o Shub-Niggurath.

Es gracioso porque el protagonista lovecraftiano clásico no dista mucho de Black, ni siquiera en su diferencia. No porque ellos, o Lovecraft, también sean gays, no vamos a meternos en ese berenjenal, sino porque, en cierto modo, ellos también pertenecen a una suerte de minoría, o, por lo menos, conciben que hay algo que les separa del mundo. Si bien esta diferencia no es siempre expresada en voz alta, se intuye plenamente en los intercambios epistolares y en las relaciones que mantienen con sus colegas. Gente que se refugia en el academicismo, en el conocimiento monotemático de una materia y en los libros para protegerse del mundo, siendo conscientes perfectamente de que ellos son diferentes o, por lo menos, que no son del todo entendidos por la gente común. En definitiva y para entendernos: que son unos friquis. 
Entramos en el mundo de la numismática, de los hikikomoris, de los que «persiguen el misterio», como los llama Íker Jiménez, del esoterismo o de cualquier otra tendencia o afición cuyos conocimientos puedan suponer alguna forma de rechazo por parte de, digamos, la comunidad más mainstream y, al mismo tiempo, una manera de encontrar gente que comparte los mismos intereses. Simultáneamente, un acto de condenación, pero también de salvación. Por mucho que queramos usar las palabras «racismo» $\mathrm{y}$ «homofobia» para relacionar la obra de Lovecraft con su vida, quizá el vínculo más importante que podamos encontrar entre lo que él fue y lo que escribió sea, precisamente, esta búsqueda de un igual, de un interlocutor con quien poder compartir lo que conocía. No en vano, Lovecraft tuvo una vida epistolar tan intensa o más que la de sus protagonistas. Allí donde Charles Dexter Ward se carteaba con otros alquimistas, H. P. Lovecraft buscaba amigos a distancia con quien pudiera hablar de mitología, de literatura fantástica y de terror, de los fanzines donde él y sus conocidos publicaban... En el fondo, lo que Ward y Lovecraft buscaban era lo mismo.

Por eso, lo que hace Moore en Providence no se trata de recontextualizar, sino de hacer explícitas las consecuencias lógicas de la situación que hemos descrito. Si huyes de ti mismo y, al mismo tiempo, huyes del rechazo, al encontrarte con otros que son como tú o, al menos, con otros que, como tú, son rechazados también por los demás y comparten contigo cierta curiosidad por la diferencia, lo lógico en esa situación sería... empezar a sentirse bien, ¿no? Pues eso es justamente lo que le pasa a Robert Black: que la gente pez que conoce en Salem-Innsmouth le cae bien, que la monstruosa familia de Athol-Dunwich también tiene su ternura y que, bueno, resucitar cadáveres para hablar con ellos tampoco es que sea un atentado contra los derechos humanos, ¿no? Mientras no haga daño a nadie, lo que hace Charles Dexter Ward tiene su punto de admirable. O, si no, que se lo pregunten a cualquier historiador.

En esa búsqueda de lo oculto que supone la trayectoria literaria de Lovecraft, hay algo de horrible; pero también se puede asumir un punto de vista mucho más positivo, que es el que al final acaba asumiendo Providence y que el ensayista y autor Fritz Leiber Jr. supo ver muy bien. Lo expresa claramente cuando se refiere, de nuevo, a los terribles monstruos de «El que susurra en la oscuridad». Porque los Mi-Go no quieren matar a aquellos que les descubren, sino llevárselos a su planeta para compartir conocimientos con ellos:

Este gesto tan encantador de los Mi-Go, que surcan el espacio sujetando contenedores, bajo un ala plegada o prensándolos con sus maternales pinzas, donde llevan los cerebros de aquellos que no tienen la misma suerte de poder soportar el vacío con sus cuerpos... Lo cierto es que la historia presenta esto con horror, pero si uno lo piensa dos veces, ese tipo de inmortalidad también tiene su atractivo. ${ }^{9}$

Así que, si el ser diferente le permite a uno ingresar en un club que puede asegurarle la inmortalidad, ¿qué hay de malo en los horrores que presenta Lovecraft?

${ }_{9}$ Szumsky, Ben J. S. y Joshi, S. T. Fritz Leiber and H. P. Lovecraft: Writers in the Dark. New Jersey, Wildside Press, 2003, p. 306. 


\section{Eso: ¿miedo a qué?}

Negros, homosexuales, judíos, mujeres... Casi cualquier colectivo al que —en principiono perteneciera Lovecraft estaba en el punto de mira. El sexismo y el racismo están presentes en la correspondencia de Lovecraft hasta extremos patológicos. Siempre ha parecido haber un consenso frente a su ficción. Las monstruosidades que tanto aterrorizan al profesor Dyer de En las montañas de la locura son una sublimación de esas «diferencias», de esos colectivos a los que Lovecraft señalaba en su vida real.

¿Cómo negarlo? Sin embargo, en la lectura que Moore hace de la obra de Lovecraft, ni el machismo ni el racismo parecen ponerse de relieve en Providence más que en pequeñas alusiones y notas a pie de página. Hay poco en los horrores de Providence que podamos interpretar como una sublimación negativa por parte de Lovecraft de las diferencias sociales, por el simple motivo de que su protagonista, en principio, no parece percibir la diferencia social como algo malo, con la excepción, claro está, de su propia homosexualidad.

El ser diferente inquieta a Robert Black, eso está claro, pero no es algo que le dé miedo. Entonces, ¿por qué, llegado cierto punto de sus peripecias, empieza, literalmente, a cagarse de terror? Eso ocurre después de su estancia en Manchester (New Hampshire), la ciudad que da origen al Arkham de Lovecraft. Allí le ocurren dos cosas. En primer lugar, Black ve trastocado su sentido cronológico, llegando a la conclusión de que ha "perdido» varias semanas de su estancia; es decir, se ha olvidado de ellas como si ese tiempo nunca hubiera pasado. Sin embargo, lo peor de todo es lo que le ocurre después, porque Black es violado por una muchacha de trece años llamada Elspeth. En realidad, lo que pasa es bastante más complejo: Black es poseído mentalmente por el padre de Elspeth quien, a su vez, vive dentro del cuerpo de la niña. Es entonces cuando obliga a Black a practicar el coito con ella, en un complejo juego de identidades y posesiones mutuas.

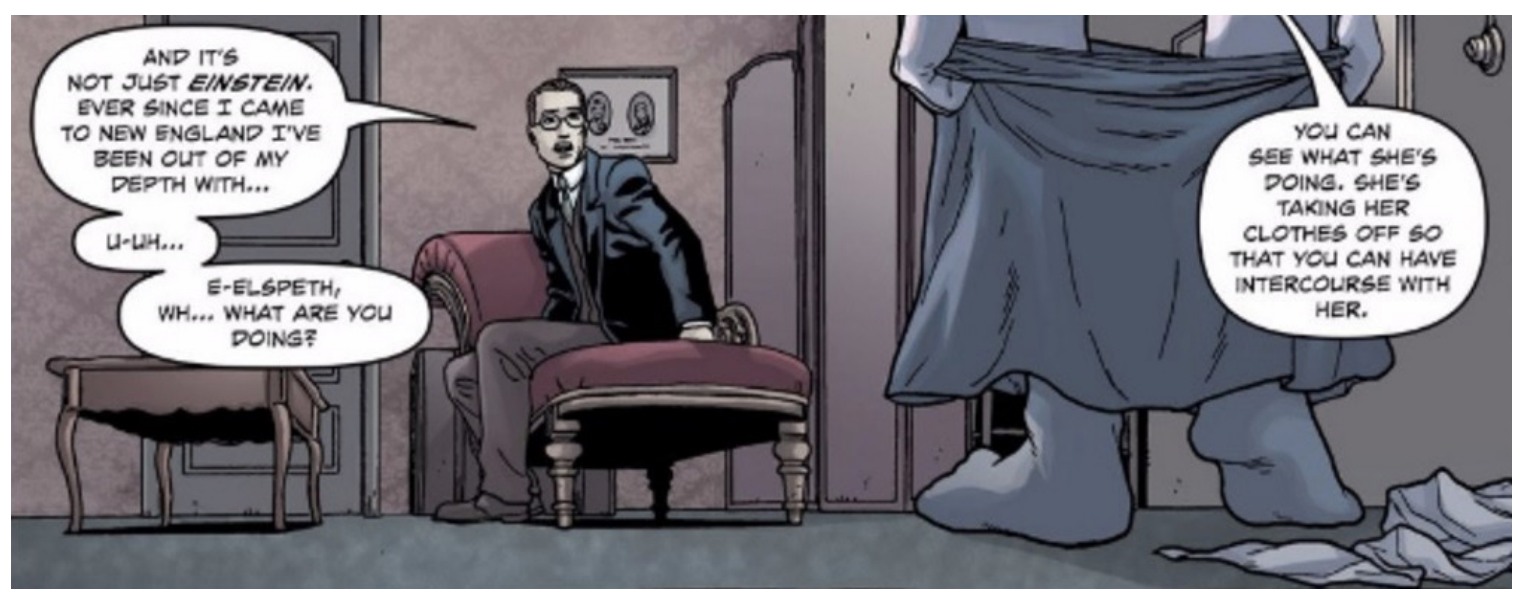

FIG. 7. Moore, A. y Burrows, J. Providence, 7.

Rantoul, Illinois, Avatar Press, 2017, p. 19. 
Esta escena, quizá la única genuinamente terrorífica en todo Providence, no es más que otro intento de llevar a sus consecuencias lógicas una premisa que Lovecraft estableció en «El ser en el umbral» («The Thing in the Doorstep», 1933). ${ }^{10}$ En ese cuento, una tal Asenath Waite se encuentra poseída por un brujo malévolo. Asenath está casada y le propone a su marido cambiar de cuerpo. Aunque el cuento no tiene en cuenta las posibilidades sexuales de la habilidad de Asenath, estas resultan obvias y Moore las explicita. En la premisa original, donde el acto de pederastia involuntaria no existe, la situación resulta tan escalofriante como la que presenta Moore. Es como esas semanas perdidas. Se «pierde» también algo en este acto sexual: se pierde uno mismo en el otro. Lo que aterroriza tanto a Robert Black no es haberse acostado con una niña; al fin y al cabo, entiende perfectamente que la niña no es una niña, sino un adulto. No ha sido él, sino el espíritu que poseía a la niña. Y para mayor inri: en realidad, no es él quien viola, sino que, al contrario, él es violado mientras ocupa el cuerpo de Elspeth.

Lo verdaderamente horrible de la escena que vive Black no tiene tanto que ver con la edad legal de la niña, sino con el hecho de que Black está sintiendo lo que siente otro cuerpo. Siente la penetración vaginal igual que la sentiría Elspeth; es decir, igual que la sentiría una niña. Lo que está presentando Moore aquí es una situación, perversa eso sí, de empatía extrema, de un trasvase sensorial y emocional completo entre dos personas. Esto es lo terrorífico. Perderse en el otro. Porque, si lo hacemos, entonces, ¿quiénes somos? Si el ser humano puede deslizarse momentáneamente fuera de su piel y vestirse con otra, ¿qué nos queda? ¿Qué hay de nuestro carácter, de esa personalidad que tanto nos ha costado forjar? Si es tan simple hacer lo que hacen Black y Elspeth Waite, entonces, ¿qué sentido tenemos nosotros como individuos?

Tanto la escena de la violación como la escena de la confusión cronológica que siente Black al llegar a Arkham tienen que ver con la pérdida de uno mismo. ¿Dónde ha estado Black durante esas semanas que ha perdido? ¿A dónde ha ido su mente? Por lo menos, durante la anterior escena Black sabía dónde estaba, pero ¿y todo ese otro tiempo? Poder dejar de ser uno mismo para volver a serlo unas semanas después es algo bastante terrorífico, como lo es un coma o un desmayo muy prolongado. Si podemos estar ausentes sin que pase nada, sin que el mundo deje de girar a nuestros pies, entonces, ¿qué importancia tiene el ser uno mismo?

Este es el primer sorbo de terror primigenio al que nos enfrenta Providence: el tipo de terror que surge cuando nos damos cuenta de que no le importamos al universo y de que nuestro papel en el esquema de las cosas es, probablemente, nulo. Es el miedo que uno siente cuando está en medio de una tormenta en el bosque y ve un rayo caer. Es el miedo del náufrago a la deriva en el océano. Al mirar un cielo estrellado particularmente claro, esos cielos en los que se puede distinguir el polvo de la Vía Láctea, se puede reaccionar con

${ }_{10}$ No confundir con «El que acecha en el umbral» («The Lurker at the Threshold», 1945, escrito por August Derleth basándose en fragmentos de Lovecraft), una novela corta que resulta ser un pastiche de «El caso de Charles Dexter Ward» y cuyo mérito principal consiste en estructurar la mitología lovecraftiana, dejando clara la relación jerárquica que existe entre los Dioses Exteriores (Yog-Sothoth, Azathoth) y los Primigenios (Cthulhu, Hastur el Innombrable, Nyarlathothep, Shub-Niggurath). 
un sentimiento de liberación al verse uno tan pequeño, o se puede reaccionar como Lovecraft y aterrorizarse ante la verdadera escala de las cosas. Es lo que llamamos lo Numinoso, y no es una casualidad que Lovecraft se preocupe tanto por ello justo en el momento en que se preocupa, entre la Primera y la Segunda Guerra Mundial. Porque lo Numinoso no tiene nada que ver con el miedo a los judíos, a los homosexuales o a los caribeños, sino con el miedo a algo mucho más trascendente. «El infierno son los otros», decía Sartre; pero no, el problema no es ese, el problema es que nosotros también somos Otro. Nuestro propio enemigo.

\section{Arriba y abajo: integrando el onirismo en el ciclo de los mitos de Cthulhu}

Freud abre la caja de Pandora y su discípulo, Jung, se asegura de que salga todo lo que hay adentro. No somos quienes creemos que somos. Y, lo que es peor, estamos formados y determinados por cosas que apenas conocemos y que están ahí desde tiempo inmemorial, enterradas en el fondo de nuestro inconsciente. Esta, la conclusión básica del pensamiento psicoanalítico, es también la premisa básica de los cuentos de Lovecraft, los cuales proceden siempre como si de una expedición arqueológica se tratara. En las montañas de la locura la arqueología es literal porque la novela versa poco más que de unos señores que se pasan todo el día explorando cavernas y sacando cosas a la luz. Y lo mismo se puede decir cuando, al contrario de lo que ocurre en esta novela, la expedición arqueológica es solo figurada: el investigador-protagonista está tirando siempre igualmente de un hilo metafórico que le hace desenterrar el pasado, desde «El caso de Charles Dexter Ward» a este Providence de Moore y Burrows.

Es curioso que alguien tan dado al exceso formal como Moore, sobre todo en Watchmen, haya decidido reducir las composiciones de página a lo más simple en Providence. Si en Watchmen Moore usaba las rejillas de nueve viñetas para hacer malabares tan complicados como los de su célebre capítulo palíndromo, en Providence se limita a combinar viñetas apaisadas que cubren todo el ancho de la página y apenas le ofrecen posibilidades combinatorias. Esta sencillez compositiva, que en algunos casos roza, de hecho, la simpleza, es una costumbre en la obra de Moore durante los últimos años. La misma estructura de viñetas apaisadas la encontramos en el Nemo de Kevin O'Neill. En Crossed +100, Gabriel Andrade combina las viñetas horizontales con viñetas cuadradas. E incluso en Fashion Beast, un cómic donde el despiece técnico de la página ni siquiera es responsabilidad de Moore, el dibujante se ciñe a lo que el mago de Northampton nos ha estado acostumbrando en los últimos años: una horizontalidad apenas fragmentada, ocasionalmente, por dos viñetas cuadradas dispuestas lado a lado. Cuando en estos cómics aparecen otro tipo de viñetas, cuadradas o incluso verticales, el cambio suele obedecer a cuestiones de ritmo, pero poco más. Providence es el primer cómic en muchos años donde las cosas son diferentes.

Providence se ciñe a lo horizontal como los anteriores títulos, pero, al contrario de lo que ocurre en estos, cuando la composición de página cambia y se inclina hacia lo vertical, es siempre por alguna razón clara. Clara y muy deliberada, porque, si obviamos las splash-pages 
o las agrupaciones de viñetas horizontales que ocasionalmente nos regala Burrows para establecer planos generales, solo en cuatro ocasiones se rompe la tónica horizontal del relato: en el capítulo dos, durante el descenso al sótano de Robert Suydam; en el capítulo siete, cuando, de nuevo, Black baja a otro sótano, en este caso el de la casa del fotógrafo Pitman; una vez más en el octavo capítulo, durante el viaje onírico con Randall Carver; y, por último, en el capítulo final, a lo largo de una panorámica compuesta por viñetas verticales que nos muestran la ciudad de Pittsburg invadida por una flora y una fauna extraterrestres que, al parecer, han venido para quedarse.

La primera secuencia de viñetas verticales, la del sótano de Suydam, nos servirá para explicar qué es lo que ocurre y por qué esa momentánea verticalidad. Bajar escaleras es un leitmotiv continuo a lo largo de Providence. Sin embargo, solo en dos ocasiones estas bajadas motivan la aparición de viñetas verticales. En otra ocasión, la del sueño compartido con Randall Carter, es una bajada metafórica de escaleras, un descenso imaginario, lo que motiva la verticalidad de la composición de página. Pero ¿por qué no utiliza Moore la misma composición vertical de página cada vez que Black sube a su habitación o cuando va a visitar a Lovecraft? Porque la composición vertical se reserva únicamente para los descensos psicológicos, no para los que son meramente instrumentales.

¿Cuántas veces hemos tenido, precisamente, una sensación de descenso o caída durante una siesta vespertina, en el límite del duermevela? ¿Es necesario preguntarle a Alicia qué es lo que piensa al respecto? La imagen de una escalera descendente, de hecho, es usada por Randall Carter como un ejercicio mental que facilita, al ir contando los escalones, la entrada en un estado hipnótico para facilitar la aparición de sueños lúcidos. Quizá el modo en que lo presenta Carter - Randolph en los cuentos de Lovecraft - es un poco fantástico, pues él asegura que de este modo se pueden conseguir sueños compartidos, e incluso caminar por un paisaje onírico común; pero si dejamos estas consideraciones más o menos fantásticas al margen, lo que está describiendo Carter no es más que una técnica que hoy en día es totalmente estándar en el campo de la hipnosis. ${ }^{11}$ No olvidemos que el Pequeño Nemo de los cómics de Winsor McCay también entraba en el mundo de los sueños - y de los sueños lúcidos, precisamente - mediante un movimiento de descenso con viñetas verticales que simulan una escalera (FIG. 9).

El primer descenso psicológico quizá sea el más revelador dentro de la trayectoria de Robert Black. En el sótano de Suydam, Black descubre una caverna rocosa y, según sigue descendiendo, empiezan a proliferar las estalactitas y las estalagmitas, hasta encontrar, en el centro de la caverna, un montón de huesos humanos esparcidos en torno a una columna de oro reluciente. Tras la columna de oro, una oscura laguna subterránea de aguas turbulentas. Al otro lado de la laguna, un muelle. Pero no hay barca para llegar a él. Black se queda mirando hacia el inaccesible muelle y es en ese momento cuando se percata de que alguien le persigue. Se trata de una criatura femenina, luminiscente y anfibia, que más adelante identifica

${ }^{11}$ Barnier, A. J. y Nash, M. R. The Oxford Handbook of Hypnosis: Theory, Research and Practice. Oxford, Oxford University Press, 2008, p. 495. 


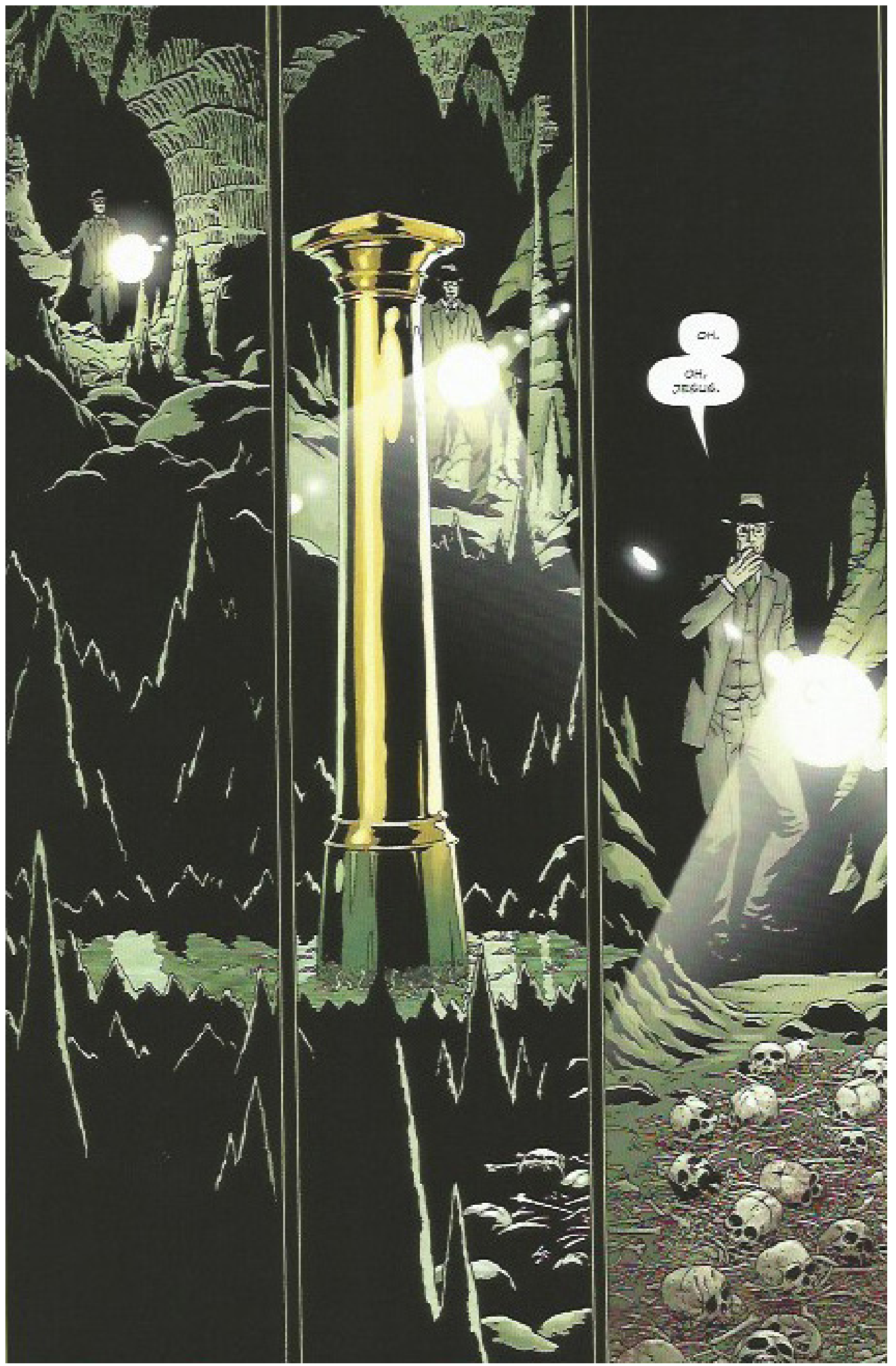

FIG. 8. Moore, A. y Burrows, J. (2016). Op. cit., ep. 2, p. 17. 


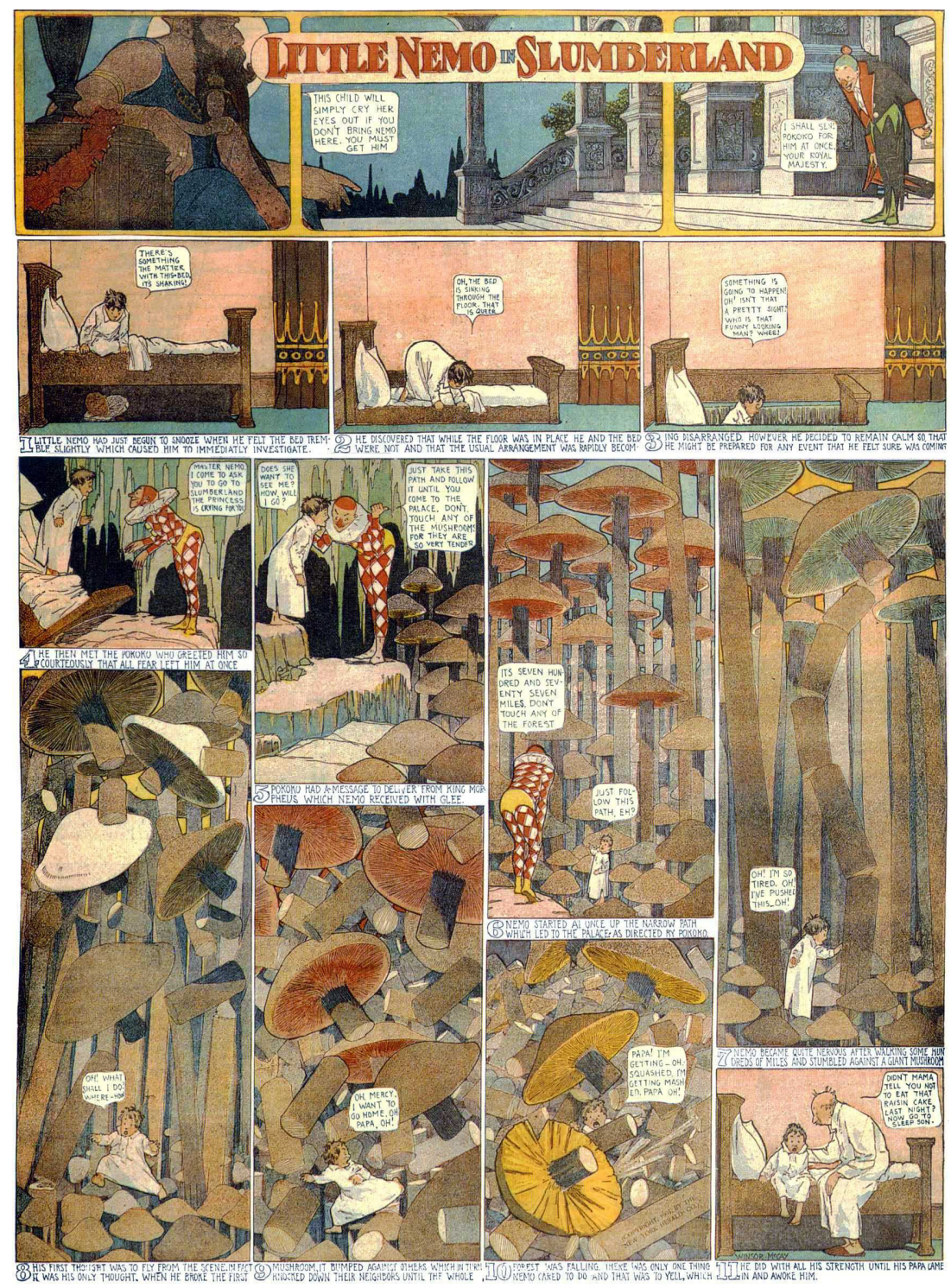

FIG. 9. McCAy, W. Little Nemo in Slumberland, 22 de octubre de 1908.

como una representación mental de su amante fallecida, Lilly. Al verla, Black empieza a correr. No puede alcanzar el muelle, por lo que corre en dirección contraria. Decisión equivocada, porque eso le obliga a escapar entre las rocas y la criatura tiene unas largas garras que le permiten escalar.

La descripción de este pasaje recuerda poderosamente a la simbología onírica que Jung usaba en su autobiografía (Recuerdos, sueños, pensamientos, ed. Seix Barral, 1964) para explicar cómo podemos distinguir dentro de un sueño el contenido personal de otro tipo de contenido: el que pertenece al inconsciente colectivo y que, por lo tanto, está enterrado en lo más profundo de nuestra psique. Los sueños que nos permiten acceder al inconsciente 
colectivo suelen contener motivos arqueológicos: se trata de desenterrar algo muy antiguo; descensos por escaleras a habitaciones ocultas, las cuales o bien pertenecen a épocas pasadas que relacionamos con nuestros ancestros, o bien son cavernas o catacumbas. No es extraño hallar en dichos lugares alguna reliquia antigua, como por ejemplo la que encontró Jung en este sueño: un sitial dorado.

[...] Entonces vi una escalera de piedra que conducía a las profundidades. Titubeante y asustado, descendí por ella. Abajo se veía una puerta con arcada románica cerrada por una cortina verde. La cortina era alta y pesada, como de tejido de malla o de brocado, y me llamó la atención su muy lujoso aspecto. Curioso por saber lo que detrás de ella se ocultaba, la aparté a un lado y vi una habitación rectangular de unos diez metros de largo, débilmente iluminada. El techo, abovedado, era de piedra y también el suelo estaba enlosado. En el centro, había una alfombra roja que iba desde la entrada hasta un estrado bajo. Sobre este, había un dorado sitial extraordinariamente lujoso. [...] Más arriba, había algo. Era una gigantesca figura que casi llegaba al techo. La figura era de extraños rasgos: de piel y carne llena de vida, y como de remate había una especie de cabeza, de forma cónica, sin rostro y sin cabellos [...] La figura no se movía; no obstante, yo tenía la sensación de que a cada instante podía descender de su tronco en forma de gusano y venir hacia mí arrastrándose. En tan apurado momento oí la voz de mi madre, como si viniera de fuera y de lo alto, que gritaba: «Sí, mírale. ¡Es el ogro!»» ${ }^{12}$

La asombrosa similitud de este pasaje onírico con el «sueño» subterráneo de Robert Black no se puede explicar por una razón de influencia. No es necesario que Moore haya leído este pasaje de Jung para reproducir el sueño, porque este pertenece a esa categoría común que son los sueños del inconsciente colectivo, donde lo que nuestro cerebro pretende transmitirnos no tiene nada que ver con acontecimientos vividos recientemente o con pulsiones psicológicas individuales, sino con fuerzas o instintos primordiales que nos afectan a todos y que están más vinculados con la geografía más antigua de nuestro cerebro - y en especial con el quartier reptiliano- que con sus partes más propiamente humanas, como, por ejemplo, el lóbulo frontal.

Estos sueños hay que encontrarlos, casi siempre, en habitaciones escondidas. Al fin y al cabo, ahí escondemos esos impulsos: en lo más hondo, en la parte más baja de nuestro cerebro, en el tronco del encéfalo y el cerebelo. Tiene fácil explicación el que estas habitaciones suelan contener alguna reliquia o un objeto antiguo - a veces, incluso aparece recubierto de polvo como si acabara de ser desenterrado- En el «sueño» de Robert Black, dicho objeto es la columna de oro, y en el de Jung, el trono o sitial también dorado. Ambos objetos están hablando de un elemento central de su ser, algo que sustenta y sostiene. De ahí que aparezcan representados por una columna o un trono. El color dorado remite a la estabilidad de dichos elementos. No en vano, el oro es inoxidable y uno de los elementos más estables de la tabla periódica. En concreto, Jung interpretaba su sueño de un modo muy similar al que Robert Black interpreta el suyo. La figura que se encuentra al lado del trono - o que surge de detrás de la columna, en el caso de Black - tiene connotaciones claramente fálicas: es alargada y se arrastra como un gusano hacia el soñador; y, en el caso de Black, es identificada literalmente con su amante Lilly. Sin embargo, ambos carecen de

12 Jung, C. Recuerdos, sueños, pensamientos. Barcelona, Seix Barral, 1964, p. 27. 
un rostro definido. En realidad, no están señalando hacia un amante real —en el caso de Jung menos aún, ya que tuvo este sueño siendo niño-, sino que apuntan hacia todas las pulsiones sexuales, en especial aquellas que la sociedad podría tildar de más «animales» y que nos vemos forzados a apartar de nuestra consciencia por motivos meramente prácticos, aunque, en ocasiones, también morales.

Pero, cuidado: no es sexo todo lo que contienen esas habitaciones y cavernas del inconsciente colectivo. El sexo es solo una parte de ello y no necesariamente la más profunda. Ahí es donde divergen Jung y Freud. Para Freud, el sexo es lo que mueve a la parte más reprimida de la psique. Para Jung, el sexo tiene una función importante, pero más aún es la que tienen una serie de conflictos y figuras de carácter universal, que él denominó arquetípicos: la figura del padre rey o padre mago, la sombra que encarna nuestro opuesto o döppelganger, la madre mala y la madre buena, el eremita que nos sirve de guía, la sacerdotisa que simboliza el conocimiento más intuitivo... En definitiva, para Freud, la fuerza más profunda del inconsciente es una fuerza amorfa e indistinta, una pulsión caótica y animal, imposible de visualizar, que él identificaba con el sexo. ¿Cómo iba a pensar otra cosa alguien que, como Freud, sufrió treinta y tres operaciones de cáncer bucal por llevar siempre un puro en los labios? ${ }^{13}$ Sin embargo, para Jung, esas fuerzas que nos mueven no son amorfas. Al contrario, están encarnadas en figuras antropomórficas concretas, que además tienen carácter universal. Todos soñamos - o alucinamos- con ellas independientemente de nuestro credo, cultura, origen o si hayamos tomado drogas o no. Las podemos encontrar en los cuentos infantiles de todo el mundo, en las leyendas y mitos, en la simbología esotérica y ocultista, en el tarot... Y si están en todos esos sitios es porque ya estaban antes en nuestros sueños.

Para Jung, el «sueño» de Black tendría fácil explicación. La columna áurea representa para Black el conocimiento, aquello que él busca y que, invariablemente, asocia con la Antigüedad; se trata de una columna dórica, el más antiguo de los órdenes clásicos. Sin embargo, no solo remite al «conócete a ti mismo» del templo de Apolo en Delfos; la columna es también un falo: representa una sexualidad con la que Black tiene problemas, porque esta le absorbe y le anula. Numerosas veces en las entradas de su diario nos detalla sus encuentros sexuales. Casi siempre entretenidos, aunque también insatisfactorios las más de las veces, Black interrumpe su vida, totalmente cautivado por el placer. En una ocasión, durante su estancia en Athol, su romance con el recepcionista del hotel — totalmente eludido en el cómic- le retiene anclado a la ciudad, sin hacer nada, durante casi una semana. Eso por no hablar de su conflicto principal, al que alude de forma constante en el diario: tanto pensar en sexo le impide, continuamente, ponerse a escribir.

Ahí reside la mayor ironía de Providence, porque Robert Black es un cretino sin parangón en la obra de Moore; como tal, es sin duda el mejor retrato psicológico de un irresponsable moral que nos haya dado jamás el Mago de Northampton, incluso más complejo que el de El Comediante. Porque, por mucho que de cuando en cuando asome la culpabilidad

${ }_{13}$ Portalatín, B. G. «El verdadero cáncer que no mató a Freud», en El Mundo, 22 de junio de2012. Disponible en: http://www.elmundo.es/elmundosalud/2012/06/18/oncologia/1340041172.html 
en alguna línea de su diario, lo único que le importa a Black es su escritura. Y si en algún momento se acuerda de Lilly, es muy difícil decir si el recuerdo está acompañado de un verdadero remordimiento, de un pesar con intención de enmienda o, por lo menos, de un intento de empatizar con los sentimientos de una persona que ha sido rechazada no tanto por su aspecto físico, sino por algo peor: por la opinión que su aspecto físico causa en la gente. No, si Black se acuerda de Lilly es para ver si puede usar ese recuerdo en el libro que planea escribir. Siempre viene bien un trauma para crear una buena motivación en un personaje, ¿verdad? Y si no que se lo digan a Alan Moore, que es quizá el autor que mejor ha sabido usar la violación como McGuffin, aquí en Providence, en Watchmen, en La broma asesina, en Lost Girls, en Jerusalem, o en casi cualquier libro suyo que abramos, por muy frívolo que resulte decirlo.

No, en realidad no es Lilly a quien se encuentra Robert Black en el sótano de Suydam. No es ella a quien representa la figura luminiscente: brillante de conocimiento, igual que la columna. La mujer fosforito es él mismo. Una representación de la parte más desaforada de su sexualidad, pero una representación también de la parte de sí mismo que más rechaza Black: su feminidad. Aquello que, en un primer momento, le atrajo de Lilly y aquello que le hizo rechazarla. Su propia otredad. Así que no es sexo todo lo que reluce: acabamos de ver que lo verdaderamente reprimido aquí es algo más que una opción sexual.

Si la obra de Lovecraft tiene alguna conexión con la realidad, es esta. Si leemos su obra de forma alegórica, podemos interpretar el miedo a los $\mathrm{Mi}-\mathrm{Go}$, los Antiguos, Cthulhu, Yog-Sothoth, lo que sea, como un miedo a lo Otro: a los negros, a los judíos, a los orientales, a las mujeres, a los homosexuales, a los demócratas, a los republicanos, a lo que uno quiera, elijan ustedes el nombre; y, sin embargo, por muchas otredades que añadamos, la interpretación se nos quedará siempre corta y apenas podrá servir para elaborar un burdo esbozo psicoanalítico de su autor. Reconozcámoslo: si los cuentos de Lovecraft se quedaran en una mera codificación en forma ficticia de los miedos reales de su autor, eso serviría para poco más que para someterle a un psicoanálisis post mortem. Pero el caso de Robert Black nos da una pista mejor sobre por dónde van los tiros. Porque Black odia a los homosexuales siendo él homosexual - haciendo explícito algo que en el Lovecraft real queda solo en el terreno especulativo- En primer lugar, odia la feminidad, tanto si es una mujer quien la exhibe, como si es un travesti. Pero, en segundo lugar, odia sin excepción a todo el que es como él; algo que se observa muy bien en los diarios: sus amantes no le merecen más que desprecio. A la larga — y no tan a la larga —, todos ellos le acaban aburriendo igual que él se aburre de sí mismo. He dicho que sin excepción, pero en realidad hay una: Tom Malone, el policía que le enseña el barrio de Red Hook, conduciéndole hacia Suydam. Pero Tom es alto, fuerte, habla con voz firme, hace gala de una cultura tan dórica como la del sótano de Suydam, y, en definitiva, cumple punto por punto todos los tópicos que podríamos esperar de un icono heterosexual de la época.

«El infierno son los Otros», decía Sartre. «Y los Otros son uno mismo», añadió Lovecraft unas décadas antes; no diciéndolo literalmente, sino entre líneas dentro de sus cuentos. Por eso, los momentos de mayor azoramiento de Robert Black son el ya mencionado encuentro 
con su femenina Sombra - un término acuñado por Jung para denominar esos encuentros oníricos con figuras que nos asustan por su radical diferencia y monstruosidad, pero que, en realidad, son uno mismo- y el intercambio de personalidades durante el acto sexual con Elspeth Wade. Es la posibilidad de perderse en el Otro lo que le aterra; la inquietante duda de que quizá no seamos quienes creemos que somos. Porque, tal vez, la diferencia que hay entre nosotros y los demás no existe. Pero, para seguir discutiendo este punto, puede ser interesante fijarnos en algunos símbolos recurrentes en este Providence y en Lovecraft en general.

\section{El símbolo arquetípico entendido por Lovecraft como monstruo primigenio}

Jung nos enseñaba que algunos símbolos, por lo menos los que denominamos arquetípicos, tienen una base biológica. ${ }^{14} \mathrm{Y}$ es esa base la que explica que encontremos dichos símbolos en casi todas las culturas, independientemente de si estas han estado en contacto o no. Por ejemplo, la tan malinterpretada y vilipendiada esvástica. Su proliferación por Europa y Asia Menor hasta la India se explica por el avance de los indoeuropeos. Pero la esvástica no es un símbolo exclusivo en la zona indoeuropea: también es un símbolo muy importante en el Este asiático y aparece en culturas y épocas sin conexión con la tradición indoeuropea, como, por ejemplo, en la zona de Ghana y Costa de Marfil ${ }^{15}$ o durante el Paleolítico, en lugares como Ucrania, mucho antes de que llegaran los indoeuropeos. ${ }^{16}$

Me imagino que los primeros antropólogos y arqueólogos que se plantearon cuestiones como esta, de tanto auge en el momento en el que Lovecraft iniciaba su carrera literaria, debieron de sentirse de forma parecida a los exploradores de En las montañas de la locura. ¿Cómo es posible que un símbolo determinado, sin apenas variaciones, haya presidido la cultura humana desde casi el inicio de los tiempos? Carl Sagan, por ejemplo, dio una explicación de lo más lovecraftiana al origen de la esvástica: fue fruto de la aparición de un cometa. Algunos cometas tienen más de una cola, y al aparecer en el cielo, cuando el cometa rota, un bólido de cuatro colas tendría una estela muy similar a la esvástica que conocemos. ${ }^{17}$ Explicación lovecraftiana, digo, porque en Lovecraft la simbología arquetípica encuentra siempre su explicación en lo cósmico: bien sea algún fenómeno de escala mayor a la terrestre, bien porque alguna civilización alienígena haya traído dichos símbolos a nuestro planeta.

${ }^{14}$ Jung insiste mucho en la necesidad de no llevar más allá de lo razonable esta base biológica de los símbolos arquetípicos. «El término "arquetipo" es con frecuencia entendido mal, como si significara ciertos motivos o imágenes mitológicas determinadas. Pero esto no son más que representaciones conscientes; sería absurdo suponer que tales representaciones [culturalmente] variables fueran hereditarias». Jung, C. El hombre y sus simbolos. Madrid, Editorial Aguilar, 1964, p. 67. Por ejemplo, la hostilidad entre hermanos es, efectivamente, un motivo arquetípico, motivado en parte por cuestiones de identidad genética, pero también en parte por la generalización de la estructura familiar neolítica. Sin embargo, visualizaciones concretas de este símbolo arquetípico, como, por ejemplo, la de Caín y Abel, deben sus detalles a una transmisión meramente cultural.

15 Polakof , C. Into Indigo: African Textiles and Dyeing Techniques. Nueva York, Anchor Books, 1980, p. 101.

16 Campbell, J. The Flight of the Wild Gander. Novato, California, New World Library, 2002, p. 17.

17 Sagan, C. y Druyan, A. Comet. Nueva York, Ballantine Books, 1985, p. 496. 
Sin embargo, la explicación más sencilla a la ubicuidad de la esvástica — confiemos en Ockham- es que, simplemente, se trata de una figura humana en movimiento. De ahí que en todas las culturas sea un símbolo ligado a la actividad, la energía, el sol, etc. Es un ser humano avanzando, con las articulaciones — rodillas, codos— doblados. Es la biología humana, la constitución de nuestro cuerpo, lo que ha impuesto la esvástica en nuestra cultura; y solo luego, en segundo lugar, son los condicionantes culturales de cada lugar los que establecen los matices que podrá tener el significado de la cruz gamada en uno u otro sitio.

Lo mismo ocurre con los pentagramas o pentáculos, los cuales, como símbolo, comparten la misma naturaleza biológica que la esvástica. ¿Por qué están presentes en todas las culturas? Por la sencilla razón de que una estrella de cinco puntas - ¿y por qué no nueve, diecisiete o veintidós? ¿Acaso las estrellas en el cielo proyectan solo cinco haces de luz? - no es más que un símbolo del cuerpo humano. Cabeza, brazos y piernas hacen cinco extremidades. E1 cuerpo humano extendido, abarcando todas las direcciones posibles, proporciona a las culturas que adoptan el símbolo del pentagrama siempre la connotación de dominio sobre el entorno y los elementos. Es una postura de dominio y, físicamente, la más estable que puede asumir el cuerpo humano, de pie y con los pies separados. Es nuestra naturaleza biológica la que condiciona el significado del signo.

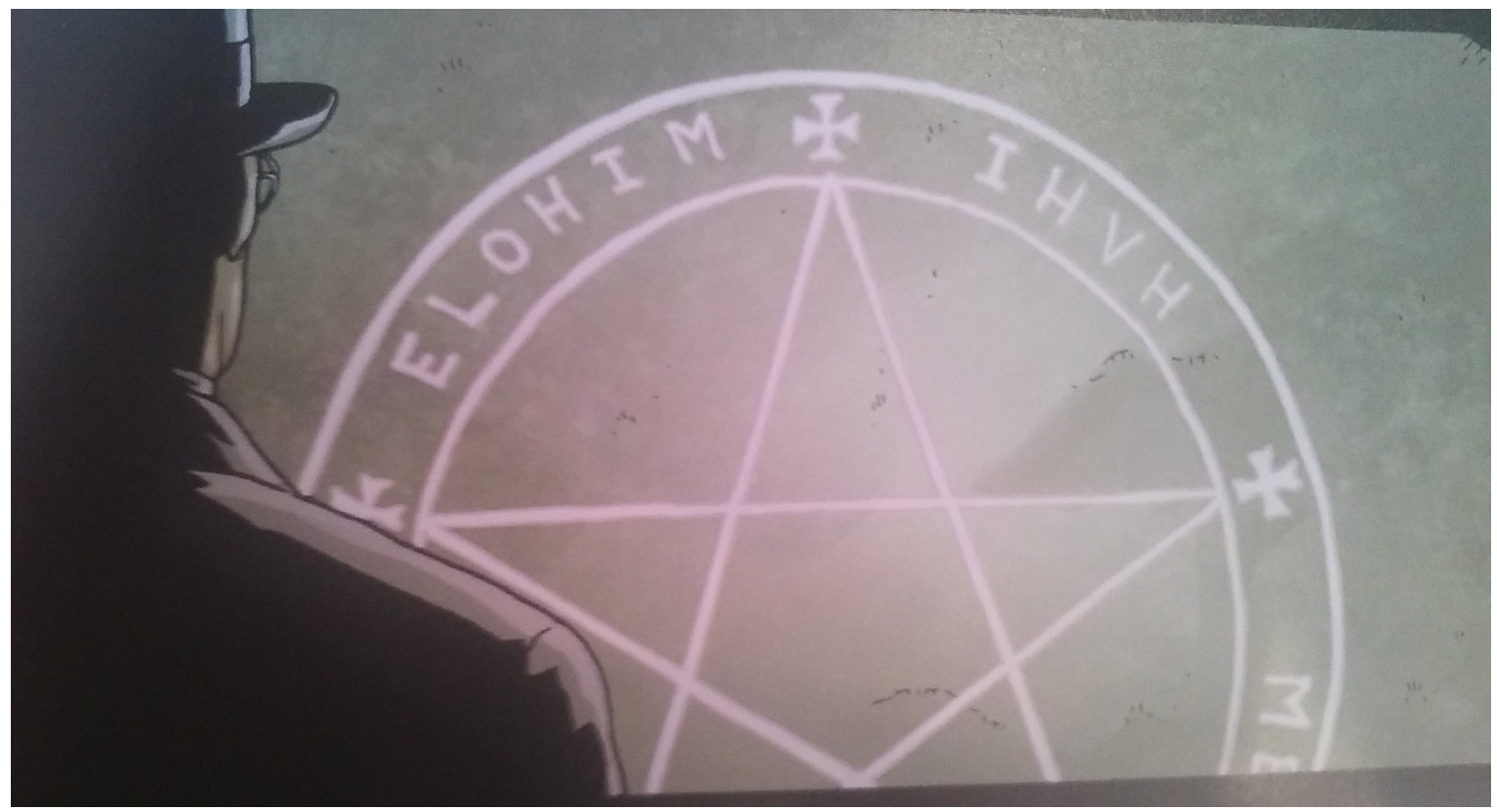

FIG. 10. Moore, A. y Burrows, J. (2016). Op. cit., ep. 2, p. 15.

Dentro de la tradición ocultista occidental, el pentagrama inscrito en un círculo, también llamado "pentáculo», tiene también ese significado de estabilidad y dominio, solo que en este caso se trata de dominio sobre los elementos. ${ }^{18} \mathrm{Y}$ es curioso que sea precisamente este

${ }^{18}$ Levi, E. Dogma y ritual de la alta magia. Madrid, Edicomunicación, 2002 [1856], p. 63. 
símbolo el que precede la primera secuencia onírica a la que se enfrenta Robert Black, pues este encuentra un pentáculo mágico — en concreto, un tetragramatón- justo al lado de las escaleras que conducen al sótano. Este tipo de pentáculo lleva escritos a lo largo de su perímetro los diferentes nombres de Dios, ${ }^{19}$ siendo, por lo tanto, un símbolo de protección, pero también un elemento ceremonial usado por magos; es decir, aquellos que tienen un dominio espiritual sobre sí mismos y sobre el entorno. Aquellos que atraviesan sin despeinarse las puertas del conocimiento, como quien se pone a cocinar quinoa. Nada más apropiado que el tetragramatón para iniciar un descenso hasta lo más profundo de su identidad, como hace Black en esta secuencia.

Lo que ocurre aquí es que ni los símbolos positivos —un pentagrama orientado hacia arriba - ni tampoco los negativos - la Sombra femenina que Black se encuentra en el sótano- son determinados por elección personal. Hasta aquí, ningún problema: al fin y al cabo, los símbolos, para que podamos usarlos y compartirlos, tienen que tener un carácter compartido. El problema es que no es la sociedad quien decide qué símbolos vamos a utilizar y cuál es su significado; al menos en lo que respecta a los símbolos de contenido arquetípico. Son ellos los que se imponen por sí mismos. O, por decirlo de otro modo, son más antiguos que nosotros y que el origen de nuestras civilizaciones.

Por eso, las teorías de Jung tienen tanto en común con Lovecraft. De hecho, hasta se ha llegado a sugerir que el tema central de la obra de ambos es, de hecho, el mismo: «el trauma de desenterrar objetos pertenecientes a una era prehumana». ${ }^{20}$ Sin ir más lejos, Lovecraft nos dio su propia interpretación de la ubicuidad del pentagrama en En las montañas de la locura, pues las estrellas de cinco puntas aparecen por todas partes en las ruinas de la ciudad escondida que los exploradores encuentran en la Antártida. En la estructura de planta de los edificios, en los símbolos de los bajorrelieves, incluso en las monedas que, al parecer, usaban los seres Primordiales, que vivían allí antes de que la humanidad o incluso el resto de seres vivos poblaran la tierra. ${ }^{21}$ ¿Por qué esa obsesión con los pentagramas? Pues porque los Antiguos, como hemos visto ya en los dibujos y descripciones anteriores, tienen en su extremo superior cinco tentáculos que hacen las veces de cabeza.

En realidad, la explicación ficcional de Lovecraft es su manera de decirnos: todos esos símbolos en los que pensamos y que tan importantes son para nuestra cultura y para nuestra identidad no nos pertenecen. No los hemos creado nosotros. No son culturales. No podemos decidir qué significan. No podemos influir sobre ellos. Las cualidades de irradiación y de movimiento de la esvástica hacen de ella un símbolo solar asociado a la actividad. Por mucho que queramos, no podemos interpretarla nunca dentro del ámbito de lo lunar y lo pasivo. El asunto de clasificar lo solar como un símbolo masculino y lo lunar como femenino ya es otro asunto bien diferente que depende, más bien, de nuestra programación

\footnotetext{
19 Crowley, A. Libro IV. Barcelona, Humanitas, 2002 [1913], p. 89.

20 Price, R. M. «Jung and Lovecraft on Prehuman Artifacts», en Crypt of Cthulhu, 5, 1982, p. 23.

${ }^{21}$ Lovecraft, H. P. y Klinger, L. S. The Annotated H. P. Lovecraft. Nueva York, Liveright, p. 528.
} 
cultural; no es lo mismo que clasificar el sol como activo y la luna como pasiva, ya que ello depende de condicionantes físicos o newtonianos, es decir, del comportamiento propio de estos astros. Hay que tener mucho cuidado con las teorías jungianas, pues cualquiera puede retorcerlas, tergiversarlas y usarlas para justificar un pensamiento socialmente establecido, como ya en su momento hizo el señor Adolf Hitler —y no es baladí la referencia directa a la esvástica nazi en el capítulo tercero de Providence.

Esa es una de las principales cuestiones cuando hablamos de los símbolos arquetípicos: todos ellos son ambivalentes - o mejor dicho, complementarios- y pueden ser vistos desde una perspectiva positiva o negativa. No solo ocurre con la esvástica, sino también con los pentagramas: el pentagrama invertido no habla del dominio sobre los elementos y la elevación del espíritu, sino de todo lo contrario: del descenso del espíritu hacia lo material, del caos y la confusión.

Y luego está el problema principal. Lo que aterra a Lovecraft de verdad. El hecho de que los contenidos de nuestra mente no nos pertenecen. El hecho de que nunca somos nosotros mismos. Y, así, se cierra el círculo. Si nuestros símbolos no son nuestros, nuestra cultura tampoco lo es. Y si nuestra cultura no es nuestra, ¿quiénes somos nosotros? De dónde vienen la esvástica, o los pentagramas, o el uróboros son cuestiones que podemos dejar para los antropólogos. Pero ¿qué ocurre con los símbolos arquetípicos que son menos abstractos? $¿$ ¿ué pasa con el viejo o la vieja que aparece en los sueños y en los cuentos de hadas? Esos sabios y hadas madrinas, ¿de dónde los hemos sacado? ¿Por qué nos da miedo o nos causa inquietud encontrarnos con grandes masas de agua cuando estamos dormidos? ¿Nos atrevemos, acaso, a sumergirnos en ellas? ¿Qué hay de esas reliquias desenterradas, habitaciones subterráneas y descensos a niveles geológicos más antiguos? ¿Por qué cuando cogemos la obra de autores tan diversos como Alan Moore, H. P. Lovecraft, David Lynch, Luis Buñuel, Ambrose Bierce o Federico García Lorca, los motivos visuales resultan tan similares? Y, sobre todo, ¿por qué nos sentimos tan chocados, tan anonadados, cuando le contamos un sueño a un amigo o a un especialista y lo interpreta con suma facilidad tan solo fijándose en dos o tres imágenes?

Porque todos tenemos el mismo sustrato simbólico. Todos los soñadores son el mismo soñador; o, como decía a propósito de la escena en que Black y Wade se acuestan: todos los amantes son el mismo amante.

Y eso, para quien no lo haya experimentado nunca, hay que decir que da bastante miedo. Nosotros somos el Otro.

\section{El fin del logos}

Por tres veces soñó Randolph Carter la maravillosa ciudad, y por tres veces fue súbitamente arrebatado cuando se hallaba en una elevada terraza que la dominaba. Brillaba toda con los dorados fulgores del sol poniente: las murallas, los templos, las columnatas y los puentes de veteado 
mármol, las fuentes de tazas plateadas y prismáticos surtidores que adornaban las grandes plazas y los perfumados jardines, las amplias avenidas bordeadas de árboles delicados, de jarrones atestados de flores y de estatuas de marfil dispuestas en filas resplandecientes. [...] El misterio envolvía la ciudad como envuelven las nubes una montaña inexplorada; y mientras Carter, con la respiración contenida, se hallaba recostado en la balaustrada de la terraza, se sintió invadido por la angustia y la nostalgia de unos recuerdos casi olvidados, por el dolor de las cosas perdidas y por la apremiante necesidad de localizar de nuevo el que algún día fuera trascendental y pavoroso lugar. ${ }^{22}$

Así daba comienzo En busca de la ciudad del sol poniente (The Dream-Quest of Unknown Kadath, 1943) y así ponía su punto final En las montañas de la locura. Con la visión de un lugar medio vislumbrado en la distancia, cuyas cumbres violáceas - en el caso de la aventura antártica - o dorados minaretes —en el del periplo onírico de Randolph Carter- solo delatan su presencia cuando las nubes que los envuelven se retiran. La actitud del narrador frente a la presencia lejana de ambos lugares es diametralmente opuesta. Para Carter, Kadath es el paraíso perdido que ha estado persiguiendo desde que era niño; sin embargo, no se trata del paraíso perdido de la infancia, el lugar donde de niño fue feliz para ser luego expulsado. Se trata de un paraíso perdido ya antes del nacimiento: un lugar mental al que la especie humana ya no puede acceder.

Por lo que respecta a las cumbres descubiertas por Dyer en la Antártida, tienen estas la misma aura primigenia de las cosas anteriores a nuestra presencia sobre la Tierra. Es algo que ya estaba cuando llegamos y que desapareció antes de que pudiéramos poner los ojos sobre ello. Dyer intuye la presencia de estos picos, los más elevados de la Tierra, y aunque no tuvo ningún reparo en mirar frente a frente a los Primordiales o a sus esclavos, los Shoggoths, elige este punto para trazar una frontera epistemológica y decir: hasta aquí hemos llegado. No quiero ver esas montañas. No quiero saber más. Me vuelvo a casa.

Las dos únicas novelas que escribió Lovecraft, En las montañas de la locura y En busca de la ciudad del sol poniente, representan las dos actitudes opuestas que se pueden asumir frente a la obra de Lovecraft.

Se presenta un gran descubrimiento: no somos quienes somos, somos otra cosa. Los contenidos mentales que se esconden bajo nuestro pensamiento están compuestos de símbolos antiquísimos, arquetípicos, cuyas formas externas han sido forjadas por nuestra cultura hace siglos, pero que, en el fondo, vienen impuestos por sus propias características biológicas o físicas. No podemos darle a un gato el significado que queramos: es un animal nocturno, lunar, cuya astucia deriva de un juego de apariencias; cuando un ser humano se alía con ellos, como hacen Lovecraft y Randolph Carter - o Carver en el episodio octavo de Providence-, es porque este humano, en cierto modo, comparte las mismas características. La personalidad y el carácter humano están condicionados por símbolos preprogramados, o, por lo menos, se sirve de estos símbolos preprogramados para conformarse y dibujarse.

${ }^{22}$ Lovecraft, H. P. Viajes al otro mundo. Ciclo de aventuras oníricas de Randolph Carter. Madrid, Alianza Editorial, 1971, p. 87. Traducción de F. Torres Oliver. 


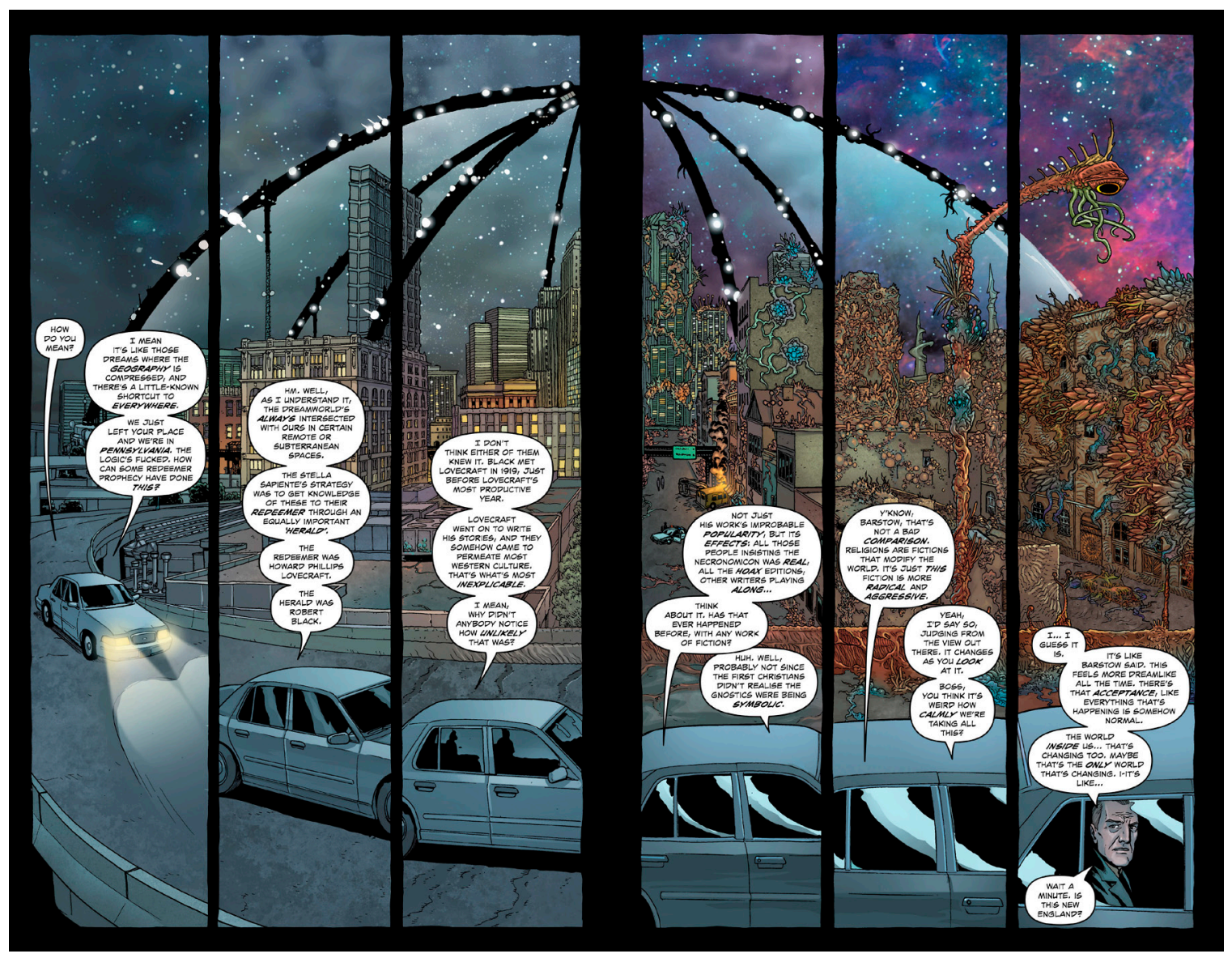

FIG. 11. Moore, A. y Burrows, J. Providence, 12. Rantoul, Illinois, Avatar Press, 2017, pp. 8-9. Lo onírico y lo arquetípico surgen de entre las profundidades de la tierra en el último episodio de Providence, haciendo que nuestra realidad se fusione con los símbolos del inconsciente colectivo. De este modo, Pittsburg se convierte, en la imagen, en una versión de Kadath. El explorador ya no tiene la elección en sus manos de ir o no ir a la ciudad onírica o a las montañas de la locura porque son ellas las que vienen a nosotros. El signo de los tiempos.

El descubrimiento de esta realidad psicológica, una realidad cuyo primer profeta teórico sigue siendo Carl Jung - por mucho que otros como Crowley o Lovecraft lo predicaran dentro de ámbitos menos respetados por la ciencia-, puede conducirnos al horror vacui de En las montañas de la locura: un no saber quiénes somos que nos hace cuestionarnos por completo a dónde vamos. Y, sin embargo, existe una segunda opción, que es el camino tomado por Randolph Carter. Si conseguimos rechazar el lenguaje racional o, por lo menos, ponerlo sistemáticamente en cuestión, entonces quizá podamos abrazar toda esa parte de nosotros que ha sido heredada simbólicamente y aceptar, al mismo tiempo, perder la individualidad y subsumirnos en el estrato colectivo al que pertenecemos. Es el ideal del taoísmo o del 
budismo místico. Perdiendo el apego a lo racional, a las explicaciones psicológicas que nos damos sobre nosotros mismos y, en definitiva, a nosotros mismos, a nuestra individualidad y a lo que creemos que somos, entonces perderemos el miedo a todo ese sustrato colectivo que tiene lo que nosotros llamamos individualidad.

En esto consiste el apocalipsis del lenguaje que Alan Moore propone en el último episodio de Providence y que, claramente, resulta en una especie de iteración del que ya propuso en Promethea.

Es el fin del lenguaje racional, o, al menos, del lenguaje racional tal y como lo conocemos. Así se lo cuenta en el último episodio de Providence Merrill Brears, la protagonista de Neonomicon, al mayor especialista en Lovecraft que hay en el mundo, S. T. Joshi - en el mundo «real», quiero decir-. Después de haber dado luz a Cthulhu, Merrill ha adquirido una perspectiva ligeramente diferente del mundo y afirma lo siguiente: «Supongo que siempre nos queda la opción de aceptar las cosas como son, como al final de "La sombra sobre Innsmouth"». Joshi le contesta: «No, en eso no puedo estar de acuerdo contigo. E1 hecho de que el narrador aparentemente acepte su destino es una manera de enfatizar el horror, pues, de este modo, Lovecraft nos señala que la mente del personaje está cambiando». Merrill admite que, si tu mente estuviera alterándose y no te dieses cuenta de ello, sería efectivamente un horror indescriptible, como puede ocurrir con el alzhéimer, añado, o con otras enfermedades degenerativas. Sin embargo, si de repente te vuelves consciente de ese cambio mental y lo aceptas...

Supongo que sí [constituiría entonces un final feliz], desde un punto de vista práctico. Además, así se alcanza la ataraxia; ese estado ideal, según Lovecraft, en el que uno se halla libre de toda ansiedad o desasosiego. Pero ¿quién de nosotros puede aceptar esto? En este mundo [nuevo] ¿hay sitio para agentes del F.B.I. o eruditos literarios? ${ }^{23}$

Por supuesto que hay sitio para todos. Pero para poder hacerse hueco es necesario adquirir la claridad de mente de Randolph Carter y darse cuenta de que las cumbres sin oxígeno de las montañas antárticas son, en realidad, un panorama de oro reluciente; que las civilizaciones antiguas enterradas bajo su hielo nos pueden enseñar muchas cosas; que podemos compartir información con nuestros amigos los $\mathrm{Mi}-\mathrm{Go}$, quienes, por otra parte, nos pueden ayudar a explorar sistemas solares exteriores al nuestro; que los símbolos arquetípicos podrían ayudarnos a comprendernos a nosotros mismos mucho mejor que interpretaciones lógicas de nuestro comportamiento, como, por ejemplo, el conductismo; o incluso que... $¿$ Cthulhu podría llegar a gobernarnos mucho mejor que Donald Trump?

Pero para llegar al estado de Carter o al del protagonista de «La sombra sobre Innsmouth», un estado en el que uno asume plenamente cosas como la validez de la magia, la escasa

${ }^{23}$ Moore, A. y Burrows, J. Providence 3: Lo innombrable. Madrid, Panini, 2017, ep. 12, p. 29. Traducción de Raúl Sastre. Las citas anteriores se refieren a la misma página. La edición de Panini de Providence no está paginada, por lo que se incluye el número del episodio para localizar mejor el pasaje en cuestión. 
diferencia que hay entre la realidad y la ficción, la validez del tarot para explicar el comportamiento humano y para predecir, como lo hace el psicoanálisis o el conductismo, sus estúpidas tendencias recurrentes; en definitiva, un estado en el que uno, de repente, recuerda que

toda la vida no es más que un conjunto de imágenes en nuestro cerebro, sin que se dé diferencia alguna entre las que nacen de las cosas reales y las engendradas por sueños que solo tienen lugar en la intimidad, ni ningún motivo para considerar las unas por encima de las otras. ${ }^{24}$

Y, para llegar a ello, hay que rechazar el logos por completo como se hace en la última viñeta de Providence. Hay que dejar de lado la dimensión lingüística, aquella parte de nosotros mismos que se basa en los símbolos que hemos creado de forma arbitraria para poder así delimitar en compartimentos nuestras nociones mentales. Y, por otro lado, hay que abrazar el símbolo numinoso, los arcanos del tarot, las imágenes que aparecen en sueños y que no podemos controlar y combinar a nuestro antojo, como sí podemos hacer con las palabras.

Creemos que con las palabras y la escritura construimos nuestra personalidad y la diferenciamos de la de los demás, pero no es así. Toda escritura está abocada al fracaso, como les ocurría a Rorschach y a Robert Black al escribir sus respectivos diarios. En Watchmen, el legado de Rorschach es encontrado en el último episodio de la serie y, pese a lo que pueda sugerir el falso happy ending de la obra, su lectura y exposición al público supondrán un apocalipsis político real. Porque si se descubre la verdad a través del testimonio de Rorschach, esto supondrá el fin de la única posibilidad de paz que le queda al mundo, la cruel posibilidad creada por Ozymandias al matar a más de un millón de personas en Nueva York. El neoliberalismo se derrumbará y el anarquismo libertario que representa Rorschach devolverá al mundo la pesadilla de la Guerra Fría. No hay solución en el logos, dice Moore. Todo sistema político, incluido el que él mismo ha abrazado, el anarquismo formalizado en una doctrina, está sujeto al lenguaje humano y a sus definiciones arbitrarias. Y, como tal, está condenado al fracaso.

Providence acaba exactamente de la misma manera que Watchmen, encontrando el diario de Robert Black. Pero aquí lo que se hace con él es justo lo contrario. En lugar de publicarlo, las páginas del diario se rompen (FIG. 12). De ese lenguaje racional dependen las fronteras que creamos alrededor de nosotros mismos para definirnos y establecer una falsa separación con los Otros. Romper esas fronteras supone el fin del lenguaje humano, el fin de los sistemas políticos, pero también el fin de nuestra identidad personal y del mundo tal y como lo conocemos. Sin embargo, parece que esa es la única solución a la que ha llegado Moore después de leer a Lovecraft bien a fondo.

No parece darnos mucho a lo que agarrarnos en Providence, pero si en algo se parece Moore a Lovecraft es en esa manía que tienen de construir sus ideas libro a libro, ladrillo a ladrillo, como una especie de work in progress. Puede que Providence nos ofrezca un fin de fiesta tan colorido como el propio Azathoth, pero si queremos saber lo que supone el fin del logos y el abrazo pleno y sin complejos de lo irracional, entonces habrá que leer Jerusalem, donde

${ }^{24}$ Lovecraft, H. P. (1971). Op. cit, p. 33. El cuento en cuestión se titula «La llave de plata». 
Moore nos habla no del proceso que ha seguido para dejar atrás lo racional, como hace en Providence, sino de lo que ha descubierto al otro lado. Una forma nueva de percibir el tiempo y de concebir los recuerdos. La misma que nos anuncia Nyarlathotep al final de Providence como si fuera el pregón de las fiestas de un pueblo.

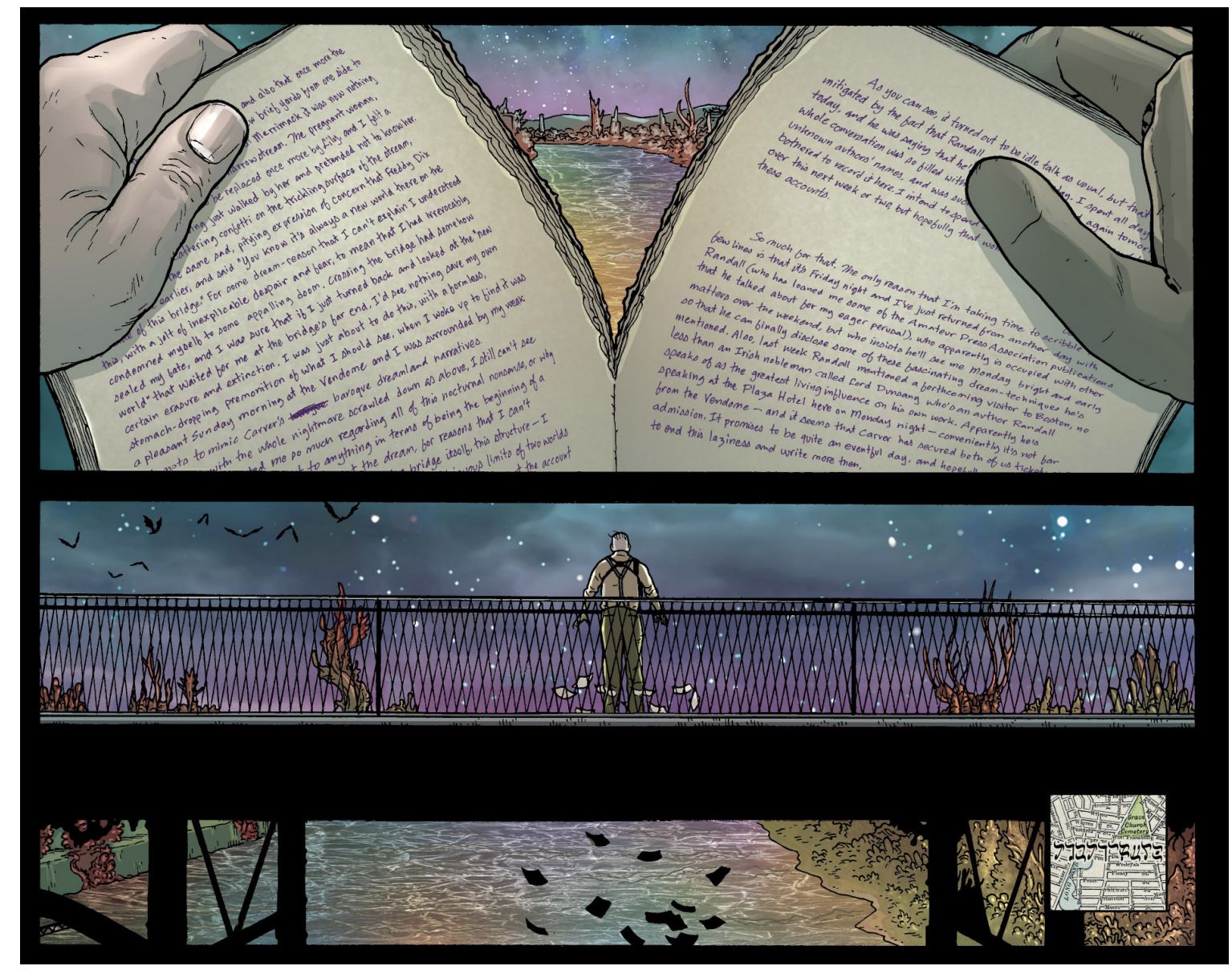

FIG. 12. Ibid., p. 34. Las últimas viñetas de Providence son una repetición de las primeras, con una diferencia: al romper el diario de Black se vislumbra, al fondo, el paisaje de ensueño en que se ha convertido la realidad. Al retirar las páginas, se produce una sustitución de la palabra por lo arquetípico - la vista del río Merrimack, ahora Miskatonic-, o, por decirlo de otra manera, de lo lingüístico por lo puramente semiótico. 


\section{Bibliografía}

Barnier, A. J. y Nash, M. R. The Oxford Handbook of Hypnosis: Theory, Research and Practice. Oxford, Oxford University Press, 2008.

Campbell, J. The Flight of the Wild Gander. Novato, California, New World Library, 2002.

Crowley, A. Libro IV. Barcelona, Humanitas, 2002 [1913].

DazA, J. L. «Providence 1: El Miedo que Acecha», en Zona Negativa, 19 de julio de 2016. Disponible en: www.zonanegativa.com/providence-miedo-acecha/

Derleth, A. y Lovecraft, H. P. «El que acecha en el umbral», en Los que vigilan desde el tiempo y otros relatos. Madrid, Alianza, 1981 [1945].

Jung, C. Recuerdos, sueños, pensamientos. Barcelona, Seix Barral, 1964.

—El hombre y sus simbolos. Madrid, Editorial Aguilar, 1964.

Levi, E. Dogma y ritual de la alta magia. Madrid, Edicomunicación, 2002 [1856].

Lovecraft, H. P. En las montañas de la locura. Madrid, Alianza, 1981 [1936]. Traducción de Fernando Calleja.

-Viajes al otro mundo. Ciclo de aventuras oníricas de Randolph Carter. Madrid, Alianza Editorial, 1971.

Lovecraft, H. P. y Klinger, L. S. The Annotated H. P. Lovecraft. Nueva York, Liveright, 2017.

McCAY, W. Little Nemo in Slumberland, 22 de octubre de 1908.

Moore, A. y Burrows, J. Providence 1: El miedo que acecha. Madrid, Panini, 2016. Traducción de Raúl Sastre.

- Providence, 3. Rantoul, Illinois, Avatar Press, 2015.

- Providence, 7. Rantoul, Illinois, Avatar Press, 2016.

- Providence, 12. Rantoul, Illinois, Avatar Press, 2017.

Moore, A. y O'Neill, K. The League of Extraordinary Gentlemen: The Black Dossier. Marietta, Georgia, Top Shelf, 2007. 
Polakoff, C. Into Indigo: African Textiles and Dyeing Techniques. Nueva York, Anchor Books, 1980.

Portalatín, B. G. «El verdadero cáncer que no mató a Freud», en El Mundo, 19 de junio de 2012. Disponible en: http://www.elmundo.es/elmundosalud/2012/06/18/oncologia/1340041172.html

Price, R. M. «Jung and Lovecraft on Prehuman Artifacts», en Crypt of Cthulhu, 5, 1982.

Solinas, A. «Camino a Providence», en Moore, A. y Burrows, J. Providence 1: El miedo que acecha. Barcelona, Panini, 2016.

Szumsкy, B. J. S. y Joshi, S. T. Fritz Leiber and H. P. Lovecraft: Writers in the Dark. New Jersey, Wildside Press, 2003. 